\title{
Sensorless Control Technique of Open-End Winding Five Phase Induction Motor under Partial Stator Winding Short-Circuit
}

\author{
Saad Khadar ${ }^{1}$, Abdellah Kouzou, Mohamed Mounir Rezzaoui ${ }^{1}$, Ahmed Hafaifa ${ }^{1}$ \\ ${ }^{1}$ LAADI Laboratory, Faculty of Sciences and Technology, Ziane Achour University of Djelfa, \\ P. O. B. 3117, Moudjbara Street, 17000 Djelfa, Algeria \\ * Corresponding author, e-mail: kouzouabdellah@ieee.org
}

Received: 02 May 2019, Accepted: 23 June 2019, Published online: 13 September 2019

\begin{abstract}
Open-end winding induction machines are gaining more attention in the last years due to their attractive advantages in the industrial applications, where high reliability is required. However, despite their inherit robustness, they are subjected to various electrical or mechanical faults that can ultimately reduce the motor efficiency and later leads to full failure. This paper proposes a method of modeling the five phase induction machine with open end stator winding taking into consideration the short-circuit fault between turns. The fault modeling is based on the theory of electromagnetic coupling of electrical circuits. In addition, a sliding mode observer is used to estimate the speed rotor. The idea of proposed backstepping strategy is used in this paper to allow to the studied machine to continue its operating state under short circuit fault between turns. The proposed sensorless control strategy is evaluated in terms of the healthy and faulty performances through the simulation results presented in this paper. The obtained results prove that the proposed sensorless control technique allows to the open-end winding five phase induction machine to continue its operation mode under the specified fault of partial short-circuit of the stator winding. This can be a very practical situation in the industrial applications, especially in the case where the maintenance is not easy and the operation of the industrial process should not be interrupted suddenly.
\end{abstract}

Keywords

open-end winding topology, five phase induction motor, short-circuit fault between turns, sensorless control, sliding mode observer, backstepping control

\section{Introduction}

Multiphase machines have been promoted in the last few years as an attractive choice for large variable speed drives. This is due to intrinsic features against their threephase counterparts like reducing the current per phase without increasing the voltage per phase, providing higher flux density, lesser acoustic noise, lower DC-link current harmonics, improved torque quality and reduced component size due to higher power density [1-2]. Another distinguished advantage is improved reliability and continuous system operation even in the fault condition [3]. For example, a machine is able to operate if one or even two phases of the supply are lost. This brings in an added advantage over their three-phase counterparts. Indeed, electric vehicles (EVs), railroad vehicles, aircraft, ship propulsion, petrochemical or wind power generation systems [4] are examples of up-to-date real applications using multiphase machines. On the other hand, multilevel inverters become nowadays the most suitable solution to provide a variable voltage/current in industrial applications because of their high power capability [1]. Indeed, these inverters have some advantages such as reduced $d v / d t$, lower total harmonic distortion and reduced common-mode voltage [5]. In this context, it has been shown recently that combining these two concepts, especially in high power industrial application can lead to additional benefits. To benefit from the merits of the both aforementioned concepts, a combination based on opening the five-phase motor winding neutral point and supplying the motor from both ends of the winding which is known as "openend winding" by a dual two-level five-phase inverter is investigated in this paper [1]. The concept of dual twolevel five-phase inverters has been proposed in the literature with the open-end winding topology as an alternative approach to synthesize multilevel load voltage waveforms $[6,7]$. In fact, this topology offers some additional benefits over the traditional single-sided supply configurations, 
such as possibility of reducing common-mode voltage, equal power input from both sides of each winding and that there is also no need to have the machine's neutral point, possibility to have twice the effective switching frequency (depending on the modulation strategy) and certain degree of fault tolerance [1, 7-9], which improve considerably the system reliability. However, despite all its previous advantages, these machines are subject to electrical or mechanical faults that ultimately reduce the motor efficiency [10] and later leads to failure can result in the shutdown of a generating unit or production line.

There are many different types of faults that may occur in electrical drive system such as failures in the power converters (a single transistor short circuit, a phaseleg short circuit, open-phase, a loss of driving signal, a capacitor short circuit fault, and a two or three phase short circuit) [11], failures of the sensors (mechanical or electrical) [12] or failures in the electrical machine [13]. Regarding the statistics [14], $38 \%$ of faults are located in power switching devices, $53.1 \%$ in control circuits and $7.7 \%$ in external auxiliaries. Electrical machine is one of the most critical components of these systems; it is subjected to both electrical and mechanical faults due to various stresses during operating conditions, which can affect their lifespan. These faults can be classified according to their location: stator faults and rotor faults. Various surveys on motor reliability have been carried out over the years $[15,16]$, these surveys indicate that the failure percentages of various components in motors are: bearing (41\%), Stator winding (37\%), rotor faults (Broken rotor bars and end ring faults) (10\%) and others (12\%), depending on the type and size of the machine [17]. It can also be seen that the stator faults are one of the most common faults in motors and are caused by stator insulation breakdown [18], which leads to short circuit between turns. The main reasons of winding insulation deterioration as described in [19-21] and [22], are thermal stresses (aging, overloading and cycling), mechanical stresses (coil movement and strikes from the rotor, bearing failures, shaft deflection, and eccentricity problems), environmental stresses (ambient temperature and contamination) and electrical stresses, mainly related to the machine terminal voltages. All these stresses interact with each other in such a way that to degrade the insulation system. According to [23], a stator winding defects can be classified into: short-circuit between turns of the same coil, short-circuit between coils of the same phase, short-circuit between coils of different phases, short-circuit between a phase and the earth and open-circuit in a phase. In [24], the authors state that the short-circuit between turns of the same coils in stator windings represent approximately $31 \%$ of the reported faults. When this fault occurs causes extremely high current flowing in the shorted turns, leading to localized thermal overloading, and reduction in the numbers of turns [25]. The mentioned fault has negligible effects on the performance of the machine at its early stages, but the heat generated in the short-circuited turns will soon cause severe faults like phase-to-phase, coil to coil, or winding to earth short circuit [26]. These faults can damage the stator winding [7], which decreases the motor efficiency and accelerates motor degradation. Consequently, the knowledge about fault mode behavior of motor drive system is extremely important from the standpoint of improved system design, protection, and fault tolerant control, in order to prevent the catastrophic failure of the machine. Machine modeling under fault conditions is a key to predict its behavior. Instead of using the binary decision for fault detection, the analysis of stator faults can be achieved based on the structural parameters of fault knowledge model. The key point to ensure the effectiveness of these methods is to choose a model of knowledge. Indeed, the type of fault that has to be detected will be based on the model used [27]. A more precise knowledge model of the machine is necessary for an accurate analysis of the machine behavior in both healthy and faulty cases. A detailed analysis of short-circuit fault between turns requires a precise model, while retaining the ability to identify the desired parameter. These models can be the five phases model [10], which can reflect the operating of the machine over a broad frequency range.

The short circuit between turns of the same coils in stator winding is the starting point of stator winding faults. In [28] evaluated the fault performance of induction motor, which showed that the average torque would reduce and the torque ripples would increase under the fault of short circuit between turns of the same phase. Therefore, a monitoring system is becoming necessary, in order to avoid extra damages to other parts and to extend the life of the motor, and continuation of the drive systems its minimum operating performance at least until the faults are rectified. In this regard, an effective and robust control design is needed. Fault tolerant control aims in ensuring the continuous operation of the system under a degraded mode due to the presence of failures. A fault-tolerant control is characterized by its ability to maintain control performances in degraded modes [29]. 
This tolerance can be ensured for the fault studied in this paper thanks to the Backstepping control. This technique ensures the stability and the performances of the system against external (or internal) disturbances. They are capable of maintaining overall system stability and acceptable performance in both healthy and faulty operating conditions. The control stability is proved, using the Lyapunov stability theory [1]. In addition, to achieve high-precision control system for OEW-FPIM, electromechanical sensors are needed to obtain an accurate rotor speed. However, practically these speed sensors are always accompanied by certain difficulties. Consequently, the accuracy of the control system is decreased causing low reliability [1]. To overcome the drawback resulting from the speed sensor, the sensorless control technique has been proposed and applied in several applications by many researchers all over the world. This is due to its main advantages such as reducing the hardware complexity, avoiding the sensibility and the fragility of sensors [30], and increasing the system robustness and reliability [31]. For three phase induction motor, many researchers have carried out the design of sensorless Backstepping control methods of induction motor drives. These methods are based on the following schemes: a High gain observer [32]. Model Reference Adaptive System [33]. Backstepping observer [34]. Luenberger observer [35], Neuronal network observers [36] and Sliding mode observer [37]. Indeed, these methods have some problems, which need to be solved, such as the requirement of external hardware (filter design), the influence of noise and large computation burden. Among the above speed estimators, the Sliding mode observer (SMO) is very attractive for sensorless control because of its comprehensive performance including the accuracy, the robustness, the computational cost, the reduced complexity and the high reliability [37]. For an open end winding five phase induction motor, there is, so far, no literature available related to the sensorless Backstepping control based on SMO. It can be said that the proposed sensorless control of studied OEW-FPIM topology presented in this paper, is an original work that has not been treated before by the researchers.

This paper presents an accurate model by which the behavior of the open end-winding five phase induction motor (OEW-FPIM) in presence of stator faults can be successfully analyzed. It is based on the theory of electromagnetic coupling of electrical circuits (the matrix coefficients of stator resistance, stator self-inductance, mutual inductance stator-stator and mutual inductance stator-rotor). These coefficients take account the number of turns in short-circuit deducted from the total number of turns. After the modelling of the machine, taking into consideration the stator faults, it is desirable for the machine to continue operating under short circuit between turns. For this purpose, a sensorless control based on SMO is implemented to obtain the good performance with the ability to run the system before and after fault condition using a Backstepping control strategy.

The present paper is organized as follows:

- In Section 2, the modelling of OEW-FPIM under short circuit fault between turns is reviewed.

- Then, a review on the principle of the used sensorless backstepping control is explained in Section 3.

- The simulation results are presented and discussed in Section 4, where the main aim is to show the effectiveness of the proposed estimator and the proposed control scheme used in the present paper.

- Finally this paper ends with a conclusion.

\section{Open-end winding five-phase induction topology}

This section presents the modelling of the FPIM in the original reference frame, taking into consideration the short-circuit fault between turns. In addition, a detailed analysis of the dual inverter supplying the studied OEWFPIM is presented.

\subsection{Modeling of FPIM with stator faults}

A FPIM is characterized with the spatial displacement between phases of $2 \pi / 5$ degrees. The rotor is a symmetrical squirrel-cage which means that $V_{r}=0$. The mutual inductance between the stator-rotor and the rotor-stator is the same $M_{s r}=M_{r s}$. The general equations of FPIM which describe the stator circuits and rotor circuits can then be written in the original reference frame by Eqs. (1) and (2) [10]:

$$
\begin{aligned}
& {\left[V_{s}\right]=\left[R_{s}\right]\left[i_{s}\right]+\left[P \varphi_{s}\right]} \\
& {\left[V_{r}\right]=[0]=\left[R_{r}\right]\left[i_{r}\right]+\left[P \varphi_{r}\right]} \\
& {\left[\varphi_{s}\right]=\left(\left[M_{s s}\right]+\left[l_{s}\right]\right)\left[i_{s}\right]+\left[M_{s r}\right]\left[i_{r}\right]} \\
& {\left[\varphi_{r}\right]=\left[M_{r s}\right]+\left(\left[M_{r r}\right]+\left[l_{r}\right]\right)\left[i_{r}^{s}\right]}
\end{aligned}
$$

where: $R_{s}, R_{r}, M_{s s}, M_{r r}, l_{s}$ and $l_{r}$ are the stator resistance, the rotor resistance, the mutual inductance stator-stator, the mutual inductance rotor-rotor, the leakage inductance of stator, the leakage inductance of rotor, respectively. $P=d / d t$ is the derivative operator. 
The stator faults are very common faults of the electrical machines in the industrial applications [7]. These can be typically classified to different types such as open-circuit fault when winding gets break, short circuit between two coils (coil-to-coil fault), short circuit between turns of two phases (line-to-line fault), short circuit between turns of same phase (turn-to-turn fault) and short circuit between winding conductors and the stator core (coil to ground fault) [38], as shown in Fig. 1.

Among these five faults, the short-circuit tum to tum in the same coil represents the origin which causes the other faults. The persistence of the latter will promotes the emergence of other cases of short circuit [39]. A FPIM with stator winding turn fault at A-phase (A-coil) is shown in Fig. 2, the phase B, C, D and E have the same number of turns $N_{s}$ in healthy mode operation, where $N_{c c a}$ represents the number of shorted turns in A-phase.

For the study of the short-circuit fault between turns, this paper presents a method of modelling of the OEWFPIM, taking into account the changing parameters such as resistors and inductors i.e., the matrix of stator resistance and the matrix of stator inductors [7, 10, 40]. In other words, one must rewrite the stator differential equations taking into account the effect of the presented short-circuit between turns. If we take $N_{n}$ as the number of useful turns for the $i$-phase after the short-circuit and $N_{c c n}$ the number of the short-circuited turns, then $N_{s}=N_{n}+N_{c c n}$, where $N_{s}$ is the total number of turns at healthy state which is the same for all phases. So, the ratio between the number of short-circuited turns and the number of total turns is given by Eq. (3):

$k_{s n}=\frac{N_{c c n}}{N_{s}}$

The number of useful turns of the stator turns per phase, is then given by Eq. (4):

$N_{n}=N_{s}+N_{c c n}=\left(1-k_{s n}\right) N_{s}=f_{s n} N_{s}$

with: $n=a, b, c, d, e$.

It has been shown that the parameters of the different parts affected by the short-circuit are directly linked to the five coefficients $f_{s a}, f_{s b}, f_{s c}, f_{s d}$ and $f_{s e}$. Consequently, the inductances and resistance matrices will be changed by taking into account the introduced coefficients of short-circuited turns $[7,40]$. As a consequence, the faulty matrices of $\left[l_{s f}\right],\left[M_{s s f}\right],\left[M_{s f f}\right],\left[M_{r f f}\right]$ and $\left[R_{s f}\right]$ are expressed by Eqs. (5)-(7):

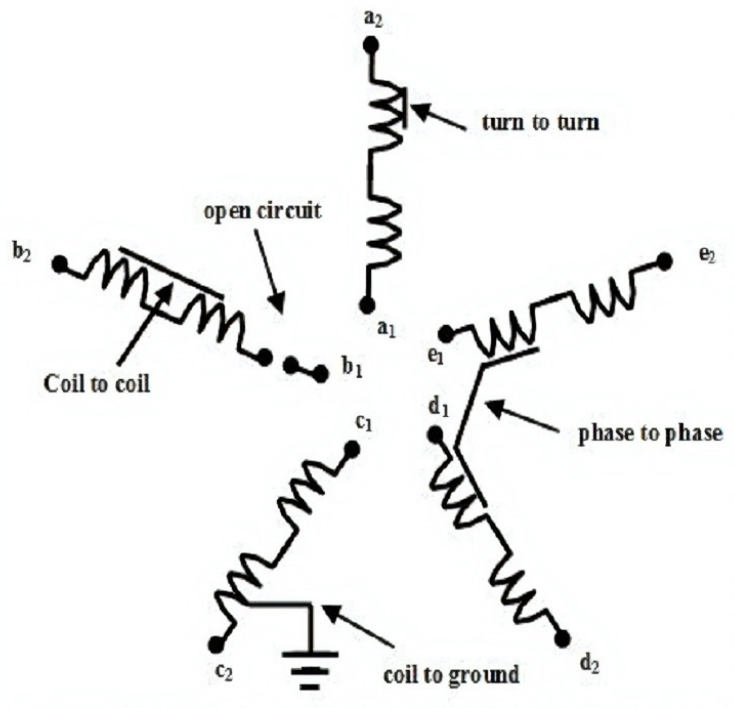

Fig. 1 The types of stator winding faults of FPIM

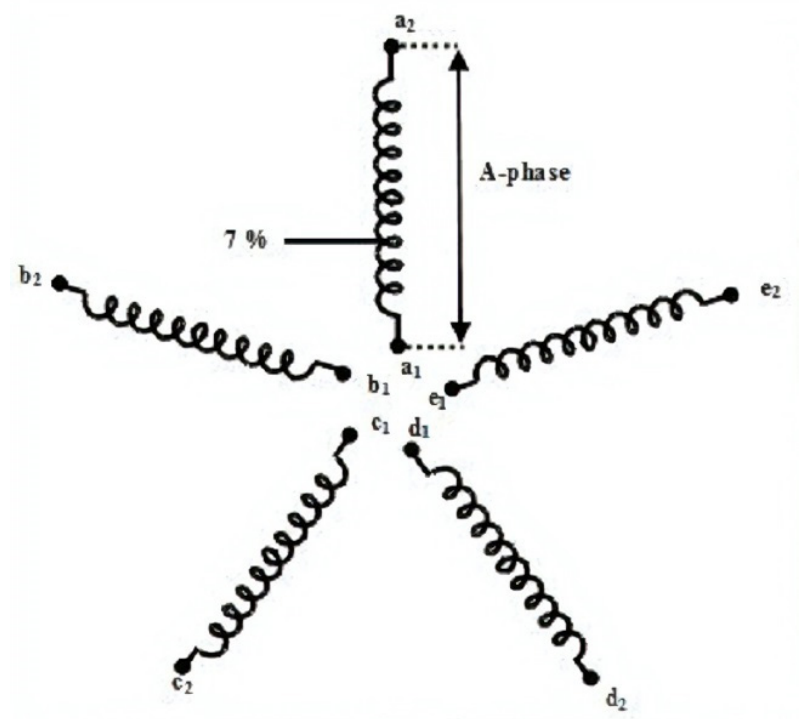

Fig. 2 Stator winding scheme with a short-circuits fault between turns in A-phase

$$
\begin{aligned}
& \left\{\begin{array}{l}
{\left[M_{s i f}\right]=\left[M_{r s f}\right]^{T}} \\
L_{s}=l_{s}+M_{s s} \\
L_{r}=l_{r}+M_{r r}
\end{array}\right. \\
& {\left[l_{s f}\right]=l_{s}\left[\begin{array}{ccccc}
f_{s a}^{2} & 0 & 0 & 0 & 0 \\
0 & f_{s b}^{2} & 0 & 0 & 0 \\
0 & 0 & f_{s c}^{2} & 0 & 0 \\
0 & 0 & 0 & f_{s d}^{2} & 0 \\
0 & 0 & 0 & 0 & f_{s e}^{2}
\end{array}\right]}
\end{aligned}
$$




$$
\left[M_{s s f}\right]=M_{s s}\left[\begin{array}{ccccc}
f_{s a}^{2} & \frac{-f_{s a} f_{s b}}{2} & \frac{-f_{s a} f_{s c}}{2} & \frac{-f_{s a} f_{s d}}{2} & \frac{-f_{s a} f_{s e}}{2} \\
\frac{-f_{s a} f_{s b}}{2} & f_{s b}^{2} & \frac{-f_{s b} f_{s c}}{2} & \frac{-f_{s b} f_{s d}}{2} & \frac{-f_{s b} f_{s e}}{2} \\
\frac{-f_{s a} f_{s c}}{2} & \frac{-f_{s b} f_{s c}}{2} & f_{s c}^{2} & \frac{-f_{s d} f_{s c}}{2} & \frac{-f_{s e} f_{s c}}{2} \\
\frac{-f_{s a} f_{s d}}{2} & \frac{-f_{s b} f_{s d}}{2} & \frac{-f_{s c} f_{s d}}{2} & f_{s d}^{2} & \frac{-f_{s e} f_{s d}}{2} \\
\frac{-f_{s a} f_{s e}}{2} & \frac{-f_{s b} f_{s e}}{2} & \frac{-f_{s c} f_{s e}}{2} & \frac{-f_{s d} f_{s e}}{2} & f_{s d}^{2}
\end{array}\right] .
$$

The resistance stator can be written by Eq. (8):

$R_{s}=R_{c c}+R_{s f}$.

The resistance of each stator phase is proportional to the number of useful turns:

$$
\left[R_{s f}\right]=R_{s}\left[\begin{array}{ccccc}
f_{s a} & 0 & 0 & 0 & 0 \\
0 & f_{s b} & 0 & 0 & 0 \\
0 & 0 & f_{s c} & 0 & 0 \\
0 & 0 & 0 & f_{s d} & 0 \\
0 & 0 & 0 & 0 & f_{s e}
\end{array}\right]
$$

where: $R_{s f}, l_{s f}, M_{s s f}, M_{s r f}$, and $M_{r s f}$ are the parameter values of motor in faulty state. $R_{c c}$ represents the effective resistance of the short-circuited turns and its value depends on the fault severity.

If the number of turns in all five stator phases are the same, the machine is balanced, so the five coefficients are equal. When the motor is running under short circuit fault between turns in A-phase only, the four coefficient corresponding to other phases are constant and equal to unity $f_{s b}=f_{s c}=f_{s d}=f_{s e}=1$, while $f_{s a}$ is not constant and it remains between 0 and 1 depending on the degree or number of short-circuited turns, all stator variables can be changed into new variables with the same pulsation. Thus, all parameters of the model will be independent of the angular position, the transformation matrix of Park $T(\theta)$ is given by Eq. (10):

$$
[T]=\left[\begin{array}{ccccc}
\cos \theta+\frac{1}{2} & \cos (\theta+\alpha)+\frac{1}{2} & \cos (\theta+2 \alpha)+\frac{1}{2} & \cos (\theta-2 \alpha)+\frac{1}{2} & \cos (\theta-\alpha)+\frac{1}{2} \\
\cos (\theta-\alpha)+\frac{1}{2} & \cos \theta+\frac{1}{2} & \cos (\theta+\alpha)+\frac{1}{2} & \cos (\theta+2 \alpha)+\frac{1}{2} & \cos (\theta-2 \alpha)+\frac{1}{2} \\
\cos (\theta-2 \alpha)+\frac{1}{2} & \cos (\theta-\alpha)+\frac{1}{2} & \cos \theta+\frac{1}{2} & \cos (\theta+\alpha)+\frac{1}{2} & \cos (\theta+2 \alpha)+\frac{1}{2} \\
\cos (\theta+2 \alpha)+\frac{1}{2} & \cos (\theta-2 \alpha)+\frac{1}{2} & \cos (\theta-\alpha)+\frac{1}{2} & \cos \theta+\frac{1}{2} & \cos (\theta+\alpha)+\frac{1}{2} \\
\cos (\theta+\alpha)+\frac{1}{2} & \cos (\theta+2 \alpha)+\frac{1}{2} & \cos (\theta-2 \alpha)+\frac{1}{2} & \cos (\theta-\alpha)+\frac{1}{2} & \cos \theta+\frac{1}{2}
\end{array}\right] .
$$




$$
\left\{\begin{array}{l}
\frac{d i_{s a}}{d t}=U_{S A}+\Delta_{a 1}+\Delta_{a 2} \\
\frac{d i_{s b}}{d t}=U_{S B}+\Delta_{b 1}+\Delta_{b 2} \\
\frac{d i_{s c}}{d t}=U_{S C}+\Delta_{c 1}+\Delta_{c 2} \\
\frac{d i_{s d}}{d t}=U_{S D}+\Delta_{d 1}+\Delta_{d 2} \\
\frac{d i_{s e}}{d t}=U_{S E}+\Delta_{e 1}+\Delta_{e 2}
\end{array}\right.
$$

The rotor flux linkage equations can be given by Eq. (15):

$$
\left\{\begin{array}{l}
\frac{d \varphi_{r a}}{d t}=\lambda \phi_{a 1}+\phi_{a 2} \\
\frac{d \varphi_{r b}}{d t}=\lambda \phi_{b 1}+\phi_{b 2} \\
\frac{d \varphi_{r c}}{d t}=\lambda \phi_{c 1}+\phi_{c 2} \\
\frac{d \varphi_{r d}}{d t}=\lambda \phi_{d 1}+\phi_{d 2} \\
\frac{d \varphi_{r e}}{d t}=\lambda \phi_{e 1}+\phi_{e 2}
\end{array}\right.
$$

The equation describing the mechanical motion of the machine is given by Eq. (16):

$J \frac{d \omega}{d t}+F \omega=T_{e}+T_{L}$

The electromagnetic torque can be found using the stator current and rotor flux by Eq. (17):

$T_{e}=n_{p} \frac{M_{s r}}{L_{r}}\left(\left[i_{s}\right] \wedge\left[\varphi_{r}\right]\right)$

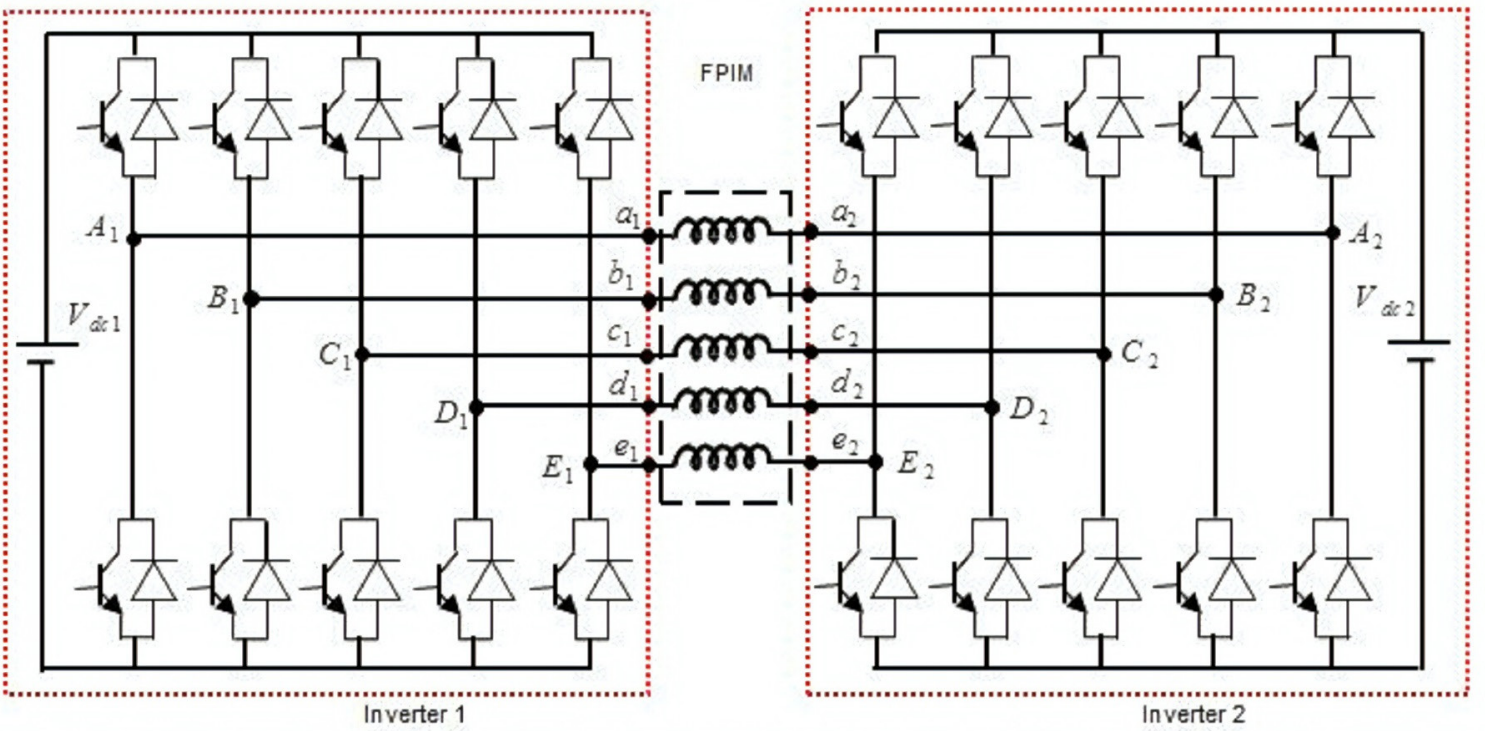

Fig. 3 Schematic diagram of dual-inverter connected OEW-FPIM with two separated DC. where: $n_{p}$ : is number of pairs of poles, $J$ : is moment of inertia of the motor and $F$ : is viscous friction coefficient.

\subsection{Open winding inverter configuration}

The structure of dual-inverter fed an OEW-FPIM is performed by opening the neutral point of the machine and supplying the machine from the both sides of the stator windings using two inverters [41]. The power circuit configuration of a two-level dual-inverter feeding an OEWFPIM is shown in Fig. 3 [1]. The two inverters are defined with indices 1 and 2 . The inverter 1 and inverter 2 outputs are denoted by symbols in capital letters $\left(A_{1}, B_{1}, C_{1}, D_{1}\right.$ and $\left.E_{1}\right)$, and $\left(A_{2}, B_{2}, C_{2}, D_{2}\right.$ and $\left.E_{2}\right)$ respectively, while the inverter 1 is connected to stator winding terminal of $a_{1}$, $b_{1}, c_{1}, d_{1}, e_{1}$ and inverter 2 is connected to stator winding terminal of $a_{2}, b_{2}, c_{2}, d_{2}, e_{2}$. It is assumed that the both inverters are fed by two separated DC power supply with the voltages of $V_{d c 1}$ and $V_{d c 2}$ which have the same value. By using this structure, the dual-inverter can be operated as a two-level, three-level or four-level inverter [41]. Indeed, this paper mainly discusses the OEW-FPIM fed by a dual-inverter with two separated DC sources. According to Fig. 3, the phase voltages of the stator winding can be expressed by Eq. (18):

$$
\left\{\begin{array}{l}
V_{s a}=V_{A 1 N 1}-V_{A 2 N 2} \\
V_{s b}=V_{B 1 N 1}-V_{B 2 N 2} \\
V_{s c}=V_{C 1 N 1}-V_{C 2 N 2} \\
V_{s d}=V_{D 1 N 1}-V_{D 2 N 2} \\
V_{s e}=V_{E 1 N 1}-V_{E 2 N 2}
\end{array}\right.
$$


where: $V_{d c 1}=V_{d c 2}$ is the equivalent single-sided supply DC source. $\left(V_{A 1 N 1}, V_{B 1 N 2}, V_{C 1 N 1}, V_{D 1 N 1}, V_{E 1 N 1}\right)$ are the five phase output voltages for inverter $1,\left(V_{A 2 N 2}, V_{B 2 N 2}\right.$, $\left.V_{C 2 N 2}, V_{D 2 N 2}, V_{E 2 N 2}\right)$ are the five phase output voltages for inverter-2.

\section{Sensorless control technique}

This section presents the sensorless control strategy used for the simulation tests. First, the backstepping control is briefly described, where no modification of this strategy is required for the faulty operation. Secondly, the SMO is presented, where it is proposed for the estimation of the rotor speed and flux is addressed.

\subsection{Backstepping control}

The backstepping technique is a systematic and recursive design methodology for nonlinear feedback control [42]. This technique is very useful for the stability of the nonlinear system $[1,43]$. It is a very powerful tool to test and find sufficient conditions for the stability of the different dynamic systems and its performances based on Lyapunov control functions $[43,44]$. In this paper, the backstepping control is based on the principle of rotor field oriented control, where the direct and quadrature components of the rotor flux fulfil the Eq. (19):

$$
\begin{aligned}
\varphi_{r d} & =\varphi_{r} . \\
\varphi_{r q} & =0 .
\end{aligned}
$$

The studied FPIM can then be described based on the standard assumptions such as the linearity of the magnetic circuit (no magnetic saturation), the balanced operating conditions, and the sinusoidal spatial distribution of the field [45]. Under these assumptions, the FPIM can be modelled in the synchronous reference frame $(d-q-x-y)$ in terms of the stator currents, the rotor flux and the mechanical equation as by Eqs. (20) and (21) [1]:

$$
\left\{\begin{array}{l}
\frac{d i_{s d}}{d t}=\alpha_{1} i_{s d}+\omega i_{s q}+\alpha_{2} \varphi_{r}+\frac{1}{\sigma L_{s}} V_{s d} \\
\frac{d i_{s q}}{d t}=\alpha_{1} i_{s q}-\omega i_{s d}+\alpha_{2} \varphi_{r}+\frac{1}{\sigma L_{s}} V_{s q} \\
\frac{d i_{s x}}{d t}=-\frac{R_{s}}{l_{s}} i_{s x}+\frac{1}{l_{s}} V_{s x} \\
\frac{d i_{s y}}{d t}=-\frac{R_{s}}{l_{s}} i_{s y}+\frac{1}{l_{s}} V_{s y}
\end{array}\right.
$$

$$
\left\{\begin{array}{l}
\frac{d \varphi_{r d}}{d t}=\frac{d \varphi_{r}}{d t}=\frac{M_{s r}}{T_{r}} i_{s d}-\frac{\varphi_{r}}{T_{r}} \\
\frac{d \varphi_{r q}}{d t}=0=\frac{M_{s r}}{T_{r}} i_{s q}-\omega_{s l} \varphi_{r} \\
\frac{d \omega}{d t}=\alpha_{3} \varphi_{r} i_{s q}-\frac{n_{p}}{J} T_{L}-\frac{F}{J} \omega
\end{array}\right.
$$

with:

$$
\begin{aligned}
& \alpha_{1}=\frac{M_{s r}^{2} R_{r}+R_{s} L_{r}^{2}}{\sigma L_{s} L_{r}^{2}}, \alpha_{2}=\frac{M_{s r} R_{r}}{\sigma L_{s} L_{r}}, \alpha_{3}=\frac{n_{p}^{2} M_{s r}}{J L_{r}}, \\
& \sigma=1-\frac{M_{s r}}{L_{s} L_{r}}, \omega=\omega_{s}-\omega_{s l} .
\end{aligned}
$$

For FPIM, the first two components $d-q$ are responsible for fluxes developing, power generation, torque production and the remaining components $x-y$ generates losses in the system. The backstepping control procedure applied in this paper on the studied machine consists of two steps.

Step 1: Computation of the reference stator currents

The first step consists in defining the errors and the dynamics of the variables to be controlled. Since the rotor speed and the rotor flux magnitude are the control variables, the tracking errors $e_{\omega}$ and $e_{\varphi}$ which respectively represent the error between rotor speed and reference speed, and the error between the rotor flux and its reference are expressed respectively by Eq. (22):

$\left\{\begin{array}{c}e_{\omega}=\omega^{*}-\omega \\ e_{\varphi}=\varphi_{r}{ }^{*}-\varphi_{r} \\ \dot{e}_{\omega}=\dot{\omega}^{*}-\dot{\omega} \\ \dot{e}_{\varphi}=\dot{\varphi}_{r}^{*}-\dot{\varphi}_{r}\end{array}\right.$.

By replacing $\dot{\omega}=d \omega / d t$ and $\dot{\varphi}_{r}=d \varphi / d t$ with their expressions presented in Eq. (21), Eq. (22) becomes:

$\left\{\begin{array}{l}\dot{e}_{\omega}=\dot{\omega}^{*}-\alpha_{3} \varphi_{r} i_{s q}+\frac{n_{p}}{J} T_{L}+\frac{F}{J} \omega \\ \dot{e}_{\varphi}=\dot{\varphi}_{r}^{*}+\frac{\varphi_{r}}{T_{r}}-\frac{M_{s r}}{T_{r}} i_{s d}\end{array}\right.$.

The first Lyapunov function $V_{1}$ is introduced, which is associated with $e_{\omega}$ and $e_{\varphi}$ it is defined by Eq. (24):

$V_{1}=\frac{1}{2}\left(e_{\omega}^{2}+e_{\varphi}^{2}\right)$

Its derivative is:

$\dot{V}_{1}=\dot{e}_{\omega} \cdot e_{\omega}+\dot{e}_{\varphi} \cdot e_{\varphi} \cdot$ 
By using Eq. (23) and Eq. (25), the derivative of the Lyapunov function is given by Eq. (26):

$$
\begin{aligned}
\dot{V}_{1} & =e_{\omega}\left(\dot{\omega}^{*}-\alpha_{3} \varphi_{r} i_{s q}+\frac{n_{p}}{J} T_{L}+\frac{F}{J} \omega\right) \\
& +e_{\varphi}\left(\dot{\varphi}_{r}^{*}+\frac{\varphi_{r}}{T_{r}}-\frac{M_{s r}}{T_{r}} i_{s d}\right) .
\end{aligned}
$$

To fit the requirement of the Lyapunov stability conditions, Eq. (26) can be reformulated by Eq. (27):

$$
\begin{aligned}
\dot{V}_{1} & =e_{\omega}\left(K_{\omega} e_{\omega}+\dot{\omega}^{*}-\alpha_{3} \varphi_{r} i_{s q}+\frac{n_{p}}{J} T_{L}+\frac{F}{J} \omega\right) \\
& -K_{\omega} e_{\omega}^{2}-K_{\varphi} e_{\varphi}^{2}+e_{\varphi}\left(K_{\varphi} e_{\varphi}+\dot{\varphi}_{r}{ }^{*}+\frac{\varphi_{r}}{T_{r}}-\frac{M_{s r}}{T_{r}} i_{s d}\right) .
\end{aligned}
$$

To ensure asymptotically the stability of the both control loops, the Lyapunov condition $\dot{V}_{1} \prec 0$ has to be satisfied, which means that the following condition have to be met:

$$
\left\{\begin{array}{l}
K_{\omega} e_{\omega}+\dot{\omega}^{*}-\alpha_{3} \varphi_{r} i_{s q}+\frac{n_{p}}{J} T_{L}+\frac{F}{J} \omega=0 \\
K_{\varphi} e_{\varphi}+\dot{\varphi}_{r}{ }^{*}+\frac{\varphi_{r}}{T_{r}}-\frac{M_{s r}}{T_{r}} i_{s d}=0 \\
K_{\omega} \succ 0 \\
K_{\varphi} \succ 0
\end{array} .\right.
$$

This yields to final form of the derivate of Eq. (24) which can be written by Eq. (29):

$$
\dot{V}_{1}=-K_{\omega} \cdot e_{\omega}^{2}-K_{\varphi} \cdot e_{\varphi}^{2} \text {. }
$$

Based on Eq. (29), the virtual control inputs presenting the stator reference currents $i_{s d}^{*}$ and $i_{s q}^{*}$, which allow generating the stabilizing functions using the stability condition of Lyapunov theory, are obtained [1]:

$$
\left\{\begin{array}{l}
i_{s d}^{*}=\frac{T_{r}}{M_{s r}}\left(K_{\varphi} e_{\varphi}+\dot{\varphi}^{*}+\frac{\varphi_{r}}{T_{r}}\right) \\
i_{s q}^{*}=\frac{1}{\alpha_{3} \varphi_{r}}\left(K_{\omega} e_{\omega}+\dot{\omega}^{*}+\frac{F \omega}{J}+\frac{T_{L} n_{p}}{J}\right)
\end{array} .\right.
$$

Step 2: Computation of the reference stator voltages

In the second step, the control law $V_{s d}, V_{s q}, V_{s x}$ and $V_{s y}$ of the whole system are determined, where the two new errors of the current stator components along $d-q$ axis and $x-y$ axis are defined by Eq. (31):

$$
\left\{\begin{array}{l}
e_{i_{s d}}=i_{s d}^{*}-i_{s d} \\
e_{i_{s q}}=i_{s q}^{*}-i_{s q} \\
e_{i_{s x}}=i_{s x}^{*}-i_{s x}^{*} \\
e_{i_{s y}}=i_{s y}^{*}-i_{s y}
\end{array}\right.
$$

Thus, the derivative of the dynamic error is obtained by Eq. (32):

$$
\left\{\begin{array}{l}
\dot{e}_{i_{s d}}=\dot{i}_{s d}^{*}-\dot{i}_{s d} \\
\dot{e}_{i_{s q}}=\dot{i}_{s q}^{*}-\dot{i}_{s q} \\
\dot{e}_{i_{s x}}=\dot{i}_{s x}^{*}-\dot{i}_{s x}^{*} \\
\dot{e}_{i_{s q}}=\dot{i}_{s y}^{*}-\dot{i}_{s y}
\end{array}\right.
$$

According to Eq. (20) and Eq. (32), the stator current errors can be expressed in the Eq. (33):

$$
\left\{\begin{array}{l}
\dot{e}_{i_{s d}}=\frac{d i_{s d}^{*}}{d t}-\alpha_{1} i_{s d}-\omega i_{s q}-\alpha_{2} \varphi_{r}-\frac{1}{\sigma L_{s}} V_{s d} \\
\dot{e}_{i_{s q}}=\frac{d i_{s q}^{*}}{d t}-\alpha_{1} i_{s q}+\omega i_{s d}-\alpha_{2} \varphi_{r}-\frac{1}{\sigma L_{s}} V_{s q} \\
\dot{e}_{i_{s x}}=\frac{d i_{s x}^{*}}{d t}-\frac{R_{s}}{l_{s}} i_{s x}-\frac{1}{l_{s}} V_{s x} \\
\dot{e}_{i_{s y}}=\frac{d i_{s y}^{*}}{d t}-\frac{R_{s}}{l_{s}} i_{s y}-\frac{1}{l_{s}} V_{s y}
\end{array} .\right.
$$

The new Lyapunov function $V_{2}$ is defined by taking into account the three errors such as the rotor speed error, the rotor flux error and the stator currents error, which is expressed by Eq. (34):

$V_{2}=\frac{1}{2}\left(e_{\varphi}^{2}+e_{\omega}^{2}+e_{i_{s d}}^{2}+e_{i_{s q}}^{2}+e_{i_{s x}}^{2}+e_{i_{s y}}^{2}\right)$.

The derivate of $V_{2}$ is written by Eq. (35):

$\dot{V}_{2}=\left(e_{\varphi} \dot{e}_{\varphi}+e_{\omega} \dot{e}_{\omega}+e_{i_{s d}} \dot{i}_{i s d}+e_{i_{s q}} \dot{e}_{s_{s q}}+e_{i_{s x}} \dot{e}_{i_{s s}}+e_{i_{s y}} \dot{e}_{i_{s y}}\right)$.

By substituting Eq. (33) into Eq. (35), while keeping the first parameters $k_{\omega}$ and $k_{\varphi}$ the same as the ones used in Eq. (29), the derivative of $V_{2}$ is rewritten by Eq. (36):

$\dot{V}_{2}=O_{1}+O_{2}+O_{3}+O_{4}+O_{5}$

with:

$$
\left\{\begin{array}{l}
O_{1}=\left(-K_{\omega} e_{\omega}^{2}-K_{\varphi} e_{\varphi}^{2}-K_{i_{s d}} e_{i_{s d}}^{2}-K_{i_{s q}} e_{i_{s q}}^{2}-K_{i_{s x}} e_{i_{s x}}^{2}-K_{i_{s y}} e_{i_{s y}}^{2}\right) \\
O_{2}=e_{i_{s d}}\left(K_{i_{s d}} e_{i_{s d}}+\frac{d i_{s d}^{*}}{d t}-\alpha_{1} i_{s d}-\omega i_{s q}-\alpha_{2} \varphi_{r}-\frac{1}{\sigma L_{s}} V_{s d}\right) \\
O_{3}=e_{i_{s q}}\left(K_{i_{s_{q}}} e_{i_{s q}}+\frac{d i_{s q}^{*}}{d t}-\alpha_{1} i_{s q}+\omega i_{s d}-\alpha_{2} \varphi_{r}-\frac{1}{\sigma L_{s}} V_{s q}\right) \\
O_{4}=e_{i_{s x}}\left(K_{i_{s x}} e_{i_{s x}}+\frac{d i_{s x}^{*}}{d t}-\frac{R_{s}}{l_{s}} i_{s x}-\frac{1}{l_{s}} V_{s x}\right) \\
O_{5}=e_{i_{s y}}\left(K_{i_{s y}} e_{i_{s y}}+\frac{d i_{s y}^{*}}{d t}-\frac{R_{s}}{l_{s}} i_{s y}-\frac{1}{l_{s}} V_{s y}\right)
\end{array} .\right.
$$


To obtain a negative derivative of the Lyapunov function $V_{2}$, the following conditions have to be satisfied:

$$
\left\{\begin{array}{l}
K_{i_{s d}} e_{i_{s d}}+\frac{d i_{s d}^{*}}{d t}-\alpha_{1} i_{s d}-\omega i_{s q}-\alpha_{2} \varphi_{r}-\frac{1}{\sigma L_{s}} V_{s d}=0 \\
K_{i_{s q}} e_{i_{s q}}+\frac{d i_{s q}^{*}}{d t}-\alpha_{1} i_{s q}+\omega i_{s d}-\alpha_{2} \varphi_{r}-\frac{1}{\sigma L_{s}} V_{s q}=0 \\
K_{i_{s x}} e_{i_{s x}}+\frac{d i_{s x}^{*}}{d t}-\frac{R_{s}}{l_{s}} i_{s x}-\frac{1}{l_{s}} V_{s x}=0 \\
K_{i_{s y}} e_{i_{s y}}+\frac{d i_{s y}^{*}}{d t}-\frac{R_{s}}{l_{s}} i_{s y}-\frac{1}{l_{s}} V_{s y}=0 \\
K_{i_{s d}} \succ 0, K_{i_{s d}} \succ 0, K_{i_{s d}} \succ 0 \text { and } K_{i_{s d}} \succ 0
\end{array} .\right.
$$

The final step in the design of the control law by defining the expressions of the control voltages which are given by the following expressions [1]:

$$
\left\{\begin{array}{l}
V_{s d}^{*}=\sigma L_{s}\left(K_{i_{s d}} e_{i_{s d}}+\frac{d i_{s d}^{*}}{d t}-\alpha_{1} i_{s d}-\omega i_{s q}-\alpha_{2} \varphi_{r}\right) \\
V_{s q}^{*}=\sigma L_{s}\left(K_{i_{s q}} e_{i_{s q}}+\frac{d i_{s q}^{*}}{d t}-\alpha_{1} i_{s q}+\omega i_{s d}-\alpha_{2} \varphi_{r}\right) \\
V_{s x}^{*}=l_{s}\left(K_{i_{s x}} e_{i_{s x}}+\frac{d i_{s x}^{*}}{d t}-\frac{R_{s}}{l_{s}} i_{s x}\right) \\
V_{s y}^{*}=l_{s}\left(K_{i_{s y}} e_{i_{s y}}+\frac{d i_{s y}^{*}}{d t}-\frac{R_{s}}{l_{s}} i_{s y}\right)
\end{array} .\right.
$$

\subsection{The sliding mode observer}

The sliding mode observer (SMO) presented in this paper, is the original one proposed in [37, 46], its basic principal is shown in Fig. 4. Indeed, the main aim of this estimation technique is to provide the estimated rotor speed and the estimated rotor flux under the assumptions that the only available input variables for the measurement are the stator currents and the supplied voltages. In addition, this structure does not require knowledge speed and rotor resistance, unlike other observers [35, 46-47]. This advantage allows the SMO to provide a good estimation of the rotor flux and the rotor speed, as well as good dynamic

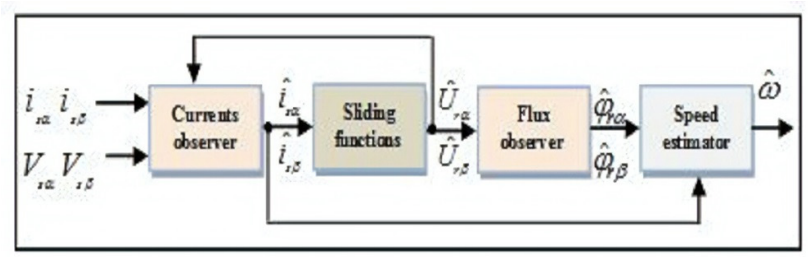

Fig. 4 Block diagram of the sliding mode observer performance over the entire speed range even under variation of these quantities. The equations of the motor are defined in the stationary frame by Eq. (40):

$\left\{\begin{array}{l}\frac{d i_{s}}{d t}=\eta U+\gamma i_{s}+\delta V_{s} \\ \frac{d \varphi_{r}}{d t}=-\left(U-\mu i_{s}\right)\end{array}\right.$.

The parameters that appear in Eq. (40) are defined as:

$i_{s}=\left[i_{s \alpha} i_{s \beta}\right]^{T}, \varphi_{r}=\left[\varphi_{r \alpha} \varphi_{r \beta}\right]^{T}, V_{s}=\left[V_{s \alpha} V_{s \beta}\right]^{T}$

$U=\left[U_{r \alpha} U_{r \beta}\right]^{T}, \delta=\left(\begin{array}{cc}w & 0 \\ 0 & w\end{array}\right), w=\frac{1}{\sigma L_{s}}, \mu=\frac{R_{r} M_{s r}}{L_{r}}$.

The function $U$ is defined by Eq. (41):

$U=\left(\begin{array}{cc}\beta_{r} & \omega \\ -\omega & \beta_{r}\end{array}\right)\left[\begin{array}{l}\varphi_{r \alpha} \\ \varphi_{r \beta}\end{array}\right]$.

The equations of the stator currents and rotor flux for the SMO model [46] can be defined by Eq. (42):

$\left\{\begin{array}{l}\frac{d \hat{i}_{s}}{d t}=\eta U+\gamma \hat{i}_{s}+\delta V_{s} \\ \frac{d \hat{\varphi}_{r}}{d t}=-\left(U-\mu \hat{i}_{s}\right)\end{array}\right.$.

The generated sliding functions are defined by Eq. (43):

$U_{r \alpha}=-k^{\prime \prime} \operatorname{sign}\left(S_{s \alpha}\right)$

$U_{r \beta}=-k^{\prime \prime \prime} \operatorname{sign}\left(S_{s \beta}\right)$

with: $S_{s \alpha}=\hat{i}_{s \alpha}-i_{s \alpha}, S_{s \beta}=\hat{i}_{s \beta}-i_{s \beta}$ and $\beta_{r}=1 / T_{r}$.

The sliding mode surface is defined by Eq. (44):

$S_{n}=\left[S_{s \alpha} S_{s \beta}\right]^{T}$.

Where $" \wedge "$ denotes the estimation value, and sign represents the signum function which is expressed by Eq. (45):

$\left\{\begin{array}{l}\operatorname{sign}(x)=1 \text { if } x \succ 0 \\ \operatorname{sign}(x)=0 \text { if } x=0 . \\ \operatorname{sign}(x)=1 \text { if } x \prec 0\end{array}\right.$

In Eq. (42) both $S_{s \alpha}$ and $S_{s \beta}$ are the sliding surface, $k^{\prime \prime}$ and $k^{\prime \prime \prime}$ are gains which represent the amplitudes of the control quantities and which are determined from the condition of existence of the sliding mode $\dot{s}_{n} \prec 0$. They are defined by Eq. (46):

$\left\{\begin{array}{l}k^{\prime \prime} \succ\left|\frac{\gamma \sigma L_{r} L_{s}}{M_{s r}} S_{s \alpha}+\frac{\varphi_{r \alpha}}{T_{r}}+\omega \varphi_{r \beta}\right| \\ k^{\prime \prime \prime} \succ\left|\frac{\gamma \sigma L_{r} L_{s}}{M_{s r}} S_{s \beta}+\frac{\varphi_{r \beta}}{T_{r}}+\omega \varphi_{r \alpha}\right|\end{array}\right.$. 
It should be noted that the gains $k^{\prime \prime}$ and $k^{\prime \prime \prime}$ are positive values and they are larger than a minimum that can be computed based on the steady state. When the system reaches the sliding surface, this means that the observed currents converge to those measured. In this case, the flux estimation is just an integration of the sliding functions and the stator currents without needing other information related to motor parameters or the rotor speed. The equivalent control of the observer is difficult to be implemented [37]. Therefore, it is reasonable to assume that equivalent control is close to the slow component of the real control that can be derived by filtering out the high frequency component using a low-pass filter [46]:

$$
\left[\begin{array}{c}
U_{r \alpha}^{e q} \\
U_{r \beta}^{e q}
\end{array}\right]=\left(\begin{array}{cc}
\frac{1}{\tau P+1} & 0 \\
0 & \frac{1}{\tau P+1}
\end{array}\right)\left[\begin{array}{c}
U_{r \alpha} \\
U_{r \beta}
\end{array}\right] .
$$

Where: $\tau$ is the time constant of the low pass filter and should be sufficiently small to preserve the slow component to be undistorted but large enough to eliminate the high frequency components. From the equivalent control concept $[37,48]$ assuming the observed currents $\hat{i}_{s \alpha}$ and $\hat{i}_{s \beta}$ must converge to those measured, from Eq. (42), Eq. (43) and Eq. (47), the Eq. (48) is obtained:

$$
\left[\begin{array}{c}
U_{r \alpha}^{e q} \\
U_{r \beta}^{e q}
\end{array}\right]=\left(\begin{array}{cc}
\beta_{r} & \hat{\omega} \\
-\hat{\omega} & \beta_{r}
\end{array}\right)\left[\begin{array}{c}
\hat{\varphi}_{r \alpha} \\
\hat{\varphi}_{r \beta}
\end{array}\right] .
$$

By using Eq. (42) and Eq. (48), the Eq. (49) is obtained:

$$
\left[\begin{array}{c}
\hat{\varphi}_{r \alpha} \\
\hat{\varphi}_{r \beta}
\end{array}\right]=-\left[\begin{array}{c}
U_{r \alpha}^{e q} \\
U_{r \beta}^{e q}
\end{array}\right]+\mu\left[\begin{array}{c}
\hat{i}_{s \alpha} \\
\hat{i}_{s \beta}
\end{array}\right] .
$$

Where, the observed fluxes $\hat{\varphi}_{r \alpha}$ and $\hat{\varphi}_{r \beta}$ can be obtained by reorganizing Eq. (48), it can be rewritten by Eq. (50):

$\left[\begin{array}{c}U_{r \alpha}^{e q} \\ U_{r \beta}^{e q}\end{array}\right]=\left(\begin{array}{cc}\hat{\varphi}_{r \alpha} & \hat{\varphi}_{r \beta} \\ \hat{\varphi}_{r \beta} & -\hat{\varphi}_{r \alpha}\end{array}\right)\left[\begin{array}{c}\hat{\beta}_{r} \\ \hat{\omega}\end{array}\right]$.

According to Eq. (48) and Eq. (50), the $\beta_{r}$ and $\hat{\omega}$ can be expressed by Eq. (51):

$$
\left[\begin{array}{c}
\hat{\beta}_{r} \\
\hat{\omega}
\end{array}\right]=\frac{1}{\left|\hat{\varphi}_{r \alpha}^{2}+\hat{\varphi}_{r \beta}^{2}\right|}\left(\begin{array}{cc}
-\hat{\varphi}_{r \alpha} & -\hat{\varphi}_{r \beta} \\
-\hat{\varphi}_{r \beta} & \hat{\varphi}_{r \alpha}
\end{array}\right)\left[\begin{array}{c}
U_{r \alpha}^{e q} \\
U_{r \beta}^{e q}
\end{array}\right] .
$$

Finally, using Eq. (50), the estimated value of the rotor speed is found by Eq. (52):

$$
\hat{\omega}=\frac{1}{\left|\hat{\varphi}_{r \alpha}^{2}+\hat{\varphi}_{r \beta}^{2}\right|}\left(\hat{\varphi}_{r \alpha} U_{r \alpha}^{e q}-\hat{\varphi}_{r \beta} U_{r \alpha}^{e q}\right) .
$$

\section{Simulation results and discussion}

In this section, simulations have been performed to validate the performances of the used sensorless backstepping technique which has been applied to the OEW-FPIM with filed oriented control based on the proposed sliding mode observer under healthy and faulty operation modes, as shown in Fig. 5. The electrical and mechanical specifications of the studied motor are as follows: $R_{s}=7.58 \Omega$, $L_{s}=0.5976 \mathrm{H}, R_{r}=6.3 \Omega, L_{r}=0.1612 \mathrm{H}, M_{s r}=0.0265 \mathrm{H}$, $n_{P}=1, J=0.0054 \mathrm{~kg} / \mathrm{m}^{2}, F=0$ N.ms.

The control system has been designed and the overall system has been simulated using the MATLAB / SIMULINK environment, where the control system has been tested under several operating conditions, such as at start-up, under load application, reverse speed, low speed, short circuit fault between turns, and parameter variation.

\subsection{Control scheme design}

The complete system block diagram of the proposed sensorless control technique based on sliding mode observer of the OEW-FPIM is presented in Fig. 5. This scheme allows eliminating the speed sensor by using an estimated speed in place of the measured one. The SMO based on the measured values of the stator currents and the stator voltages components in $(\alpha-\beta)$ frame.

\subsection{Performances evaluation during healthy mode operation}

In order to evaluate the performance and correctness of the proposed sensorless control technique based on sliding mode observer of the OEW-FPIM. In first test, the studied motor is analyzed under healthy state conditions in the whole interval $(1.5 \mathrm{~s})$. The simulation results have been obtained with no load at starting up condition. The load is applied at $t=0.5 \mathrm{~s}$ with a value of $2 \mathrm{~N}$.m. The reference speed is fixed to $300 \mathrm{rad} / \mathrm{s}$ and the reference rotor flux is fixed to $1 \mathrm{~Wb}$. Fig. 6 presents the reference, the real and the estimated speeds. One can see that the estimated and real speed follow the reference speed with a fast response time and a small overshoot. In the same time, the real speed and estimated speed are almost indistinguishable from each other. Thus, the simulation results confirm that the proposed observer gives very good results. Furthermore, the real speed is compared with the estimated one. One can notice that the maximum estimation speed error is approximately zero at steady state and it attains $0.09 \mathrm{rad} / \mathrm{s}$ as maximum value in transient state as shown in Fig. 7. The load 


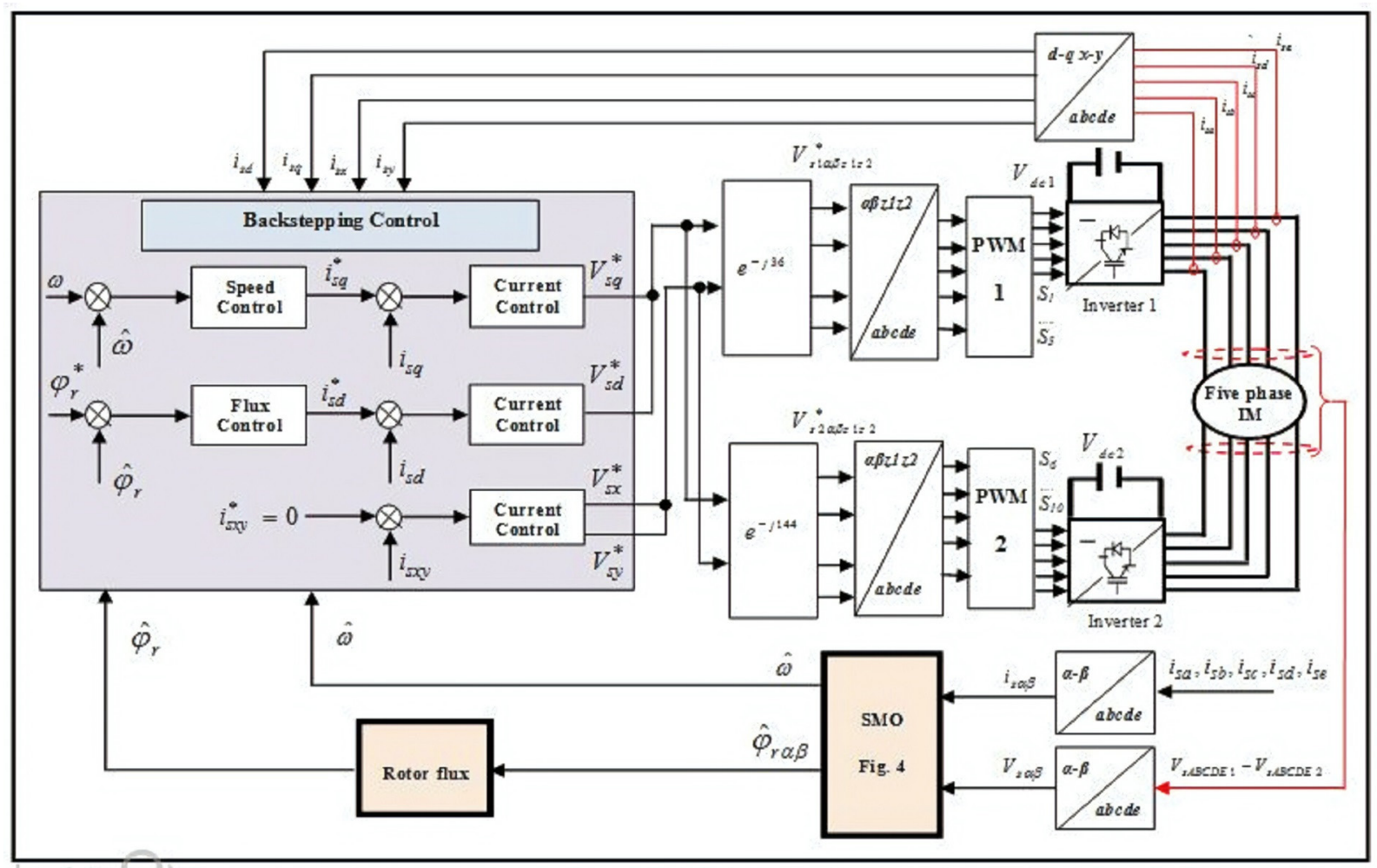

Fig. 5 The block diagram of the overall control system

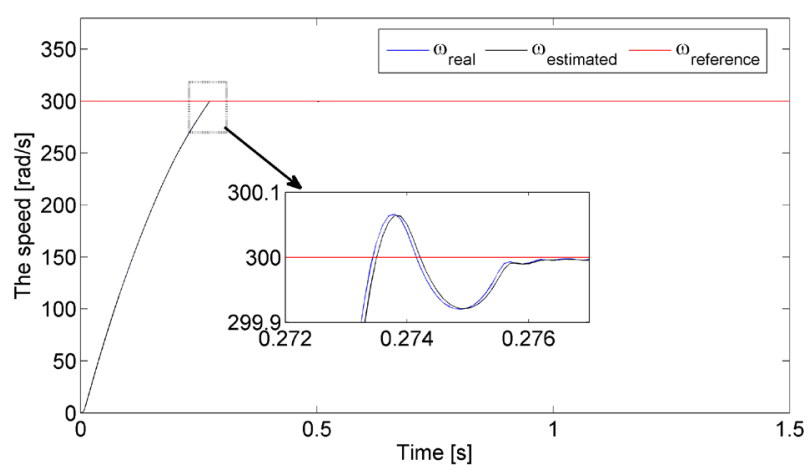

Fig. 6 The real, reference and estimated speed

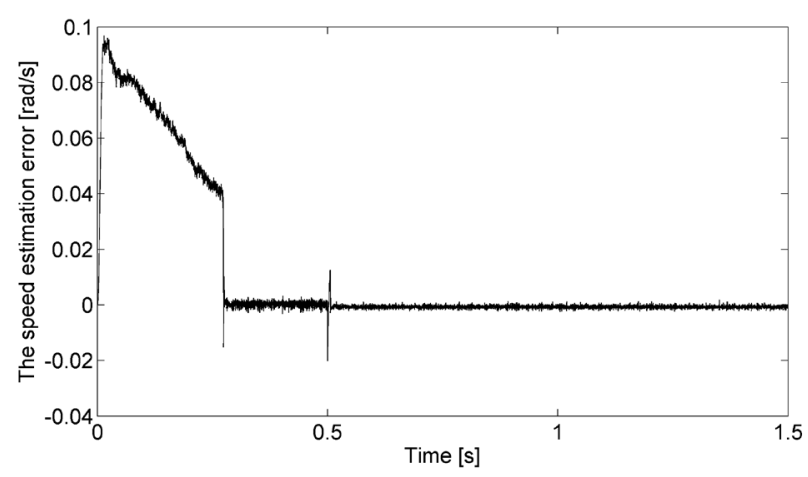

Fig. 7 The speed estimation error torque and the electromagnetic torque of OEW-FPIM are presented in Fig. 8. Where the excellent dynamic performance of torque can be noticed clearly. On the other side, beside the good response during the change of the load torque where the developed motor torque follows this last closely, the decoupling between the torque and the flux is quite good. As it is shown clearly from Fig. 9, the direct current component $\left(i_{s q}\right)$ presents an image of the rotor flux and the quadratic current component $\left(i_{s q}\right)$ presents an image of the electromagnetic torque. Fig. 10 shows the rotor flux components in $(d-q)$ reference frame where the direct rotor flux component is stabilized at the flux reference value

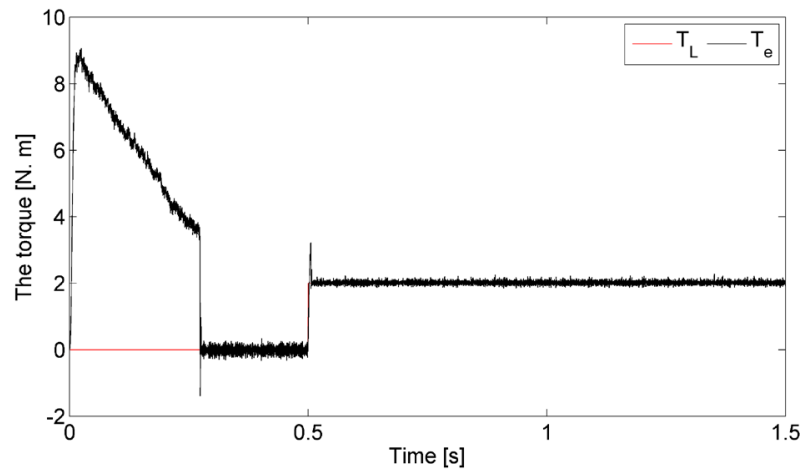

Fig. 8 The electromagnetic torque and load torque 


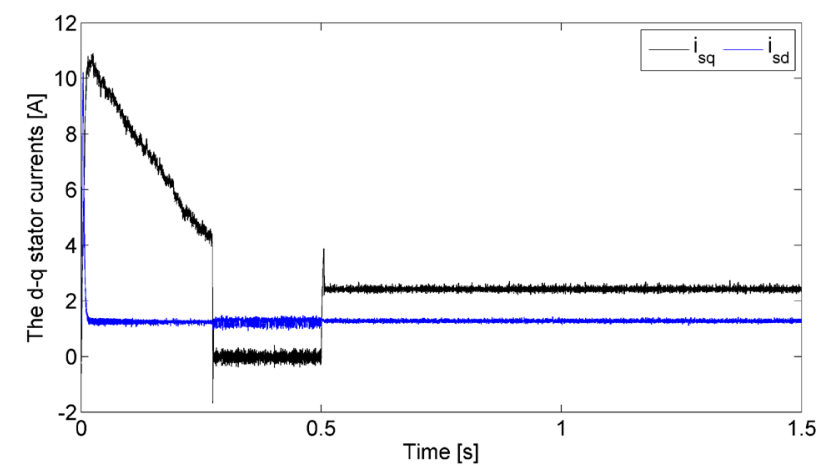

Fig. 9 The $d$ - $q$ stator currents

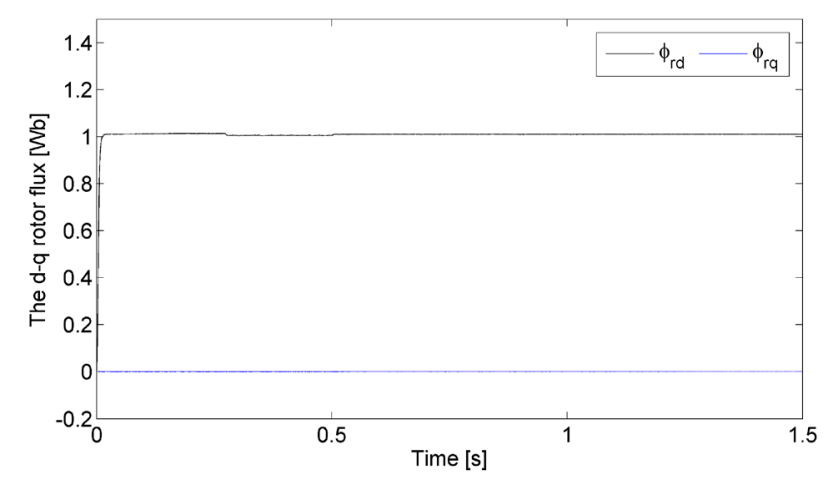

Fig. 10 The $d$ - $q$ rotor flux

$(1 \mathrm{~Wb})$, while the quadratic rotor flux component is maintained at almost null value. According to Fig. 11, one can notice that the rotor flux trajectory in the stationary $\alpha-\beta$ frame presents a circular form, which proves the sinusoidal behavior of the both components $\left(\varphi_{r \alpha}, \varphi_{\alpha \beta}\right)$.

The five phase stator currents of the OEW-FPIM are shown in Fig. 12. It is clear that the currents behave according to the dynamic behavior of the motor, which is depending on the load torque change, where a sinusoidal waveform is obtained with reduced harmonic content and the magnitude changes following the developed torque. In the same time the five phase currents are balanced as shown clearly in the zoom area of Fig. 12.

\subsection{Performances evaluation during short circuit fault between turns}

In this test, the reference speed is fixed to $300 \mathrm{rad} / \mathrm{s}$, the start-up is proceeded under no load and a load torque of $2 \mathrm{~N} . \mathrm{m}$ is applied at time $t=0.5 \mathrm{~s}$. In this test the case of a short-circuit of $7 \%$ of the turns in A-phase is taken in consideration in this study. However, the Backstepping algorithm is not affected where it is the same as the one used in the case of healthy case.

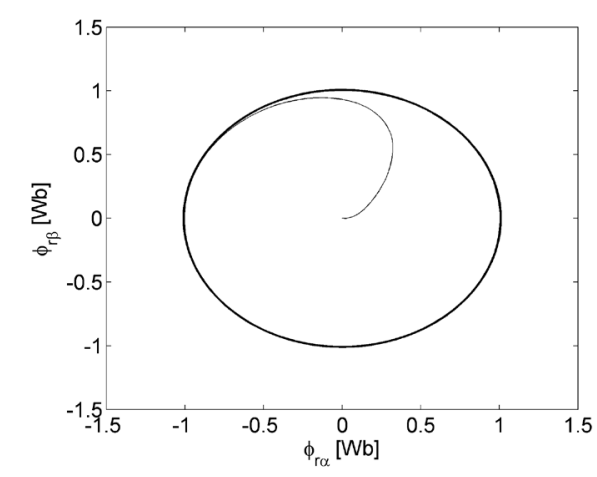

Fig. 11 The rotor flux trajectory

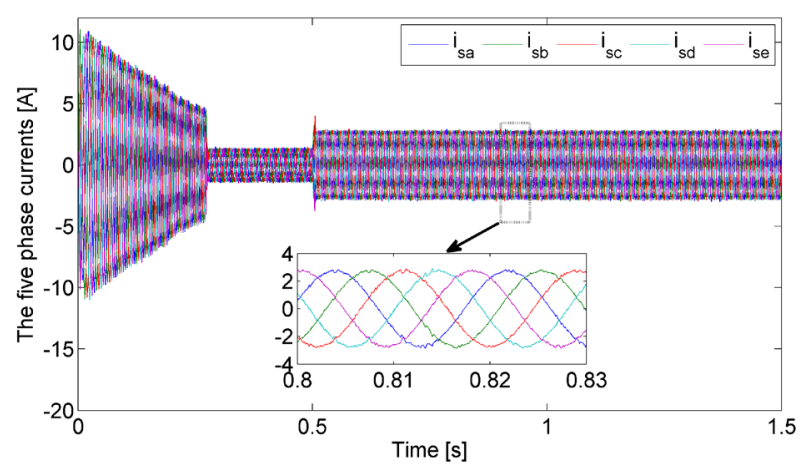

Fig. 12 The five phase motor stator currents

Fig. 13 shows the real, the reference and the estimated speed responses, while the waveforms in zoom A (see Fig. 14) presents the speed responses around the point of fault occurrence. It can be seen clearly that when the fault occurs the speed oscillates slightly around the $300.01 \mathrm{rad} / \mathrm{s}$ as shown in Fig. 14, this resulting speed oscillation is negligible as its amplitude is less than one percent, which proves the robustness of the proposed control use in this paper for the studied motor. Fig. 15 shows the electromagnetic and the load torque, while Fig. 16 presents a zoom around the point of fault occurrence. Where, it can be observed that very small fluctuations occur in the electromagnetic torque and the maximum magnitude reaches 2.4 N.m. The appearance of these oscillations is directly related to the existence of a residual asymmetry in the motor stator circuit. On the other side, these fluctuations introduce acoustic noise, and additional mechanical vibrations which may be dangerous for motor. Fig. 17 presents the five phase stator currents. Before the occurrence of the stator faults, under healthy condition, all of these currents are equal and balanced. As the fault occurs at the moment $t=1 \mathrm{~s}$ a current unbalance takes place. It can be seen that the A phase current grows $\left(i_{a s}=3.15 \mathrm{~A}\right)$ 


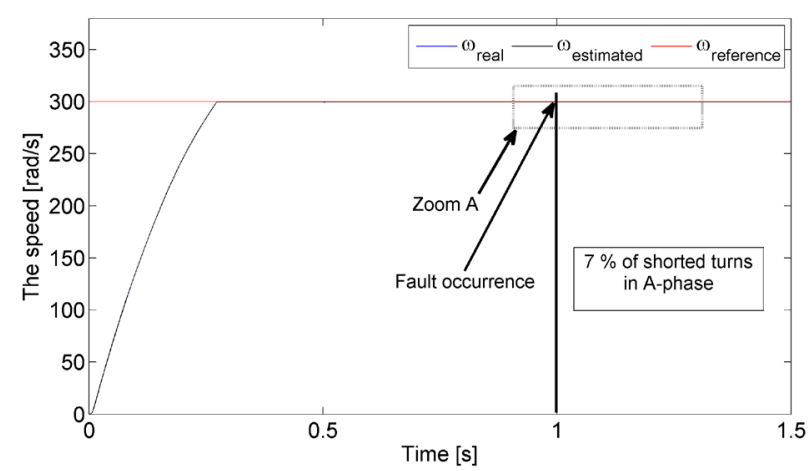

Fig. 13 The real, reference and estimated speed

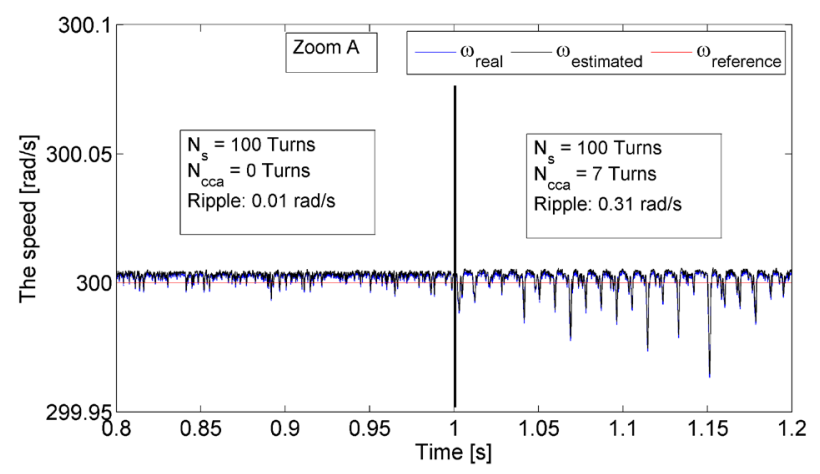

Fig. 14 The zoom A

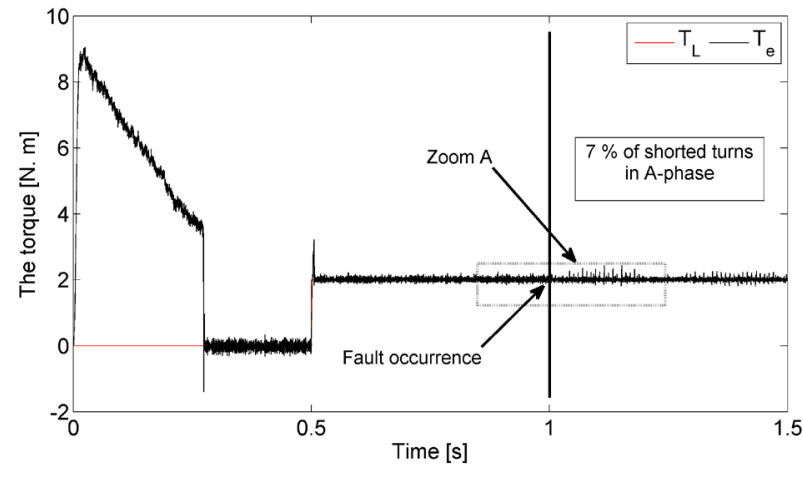

Fig. 15 The electromagnetic and load torque

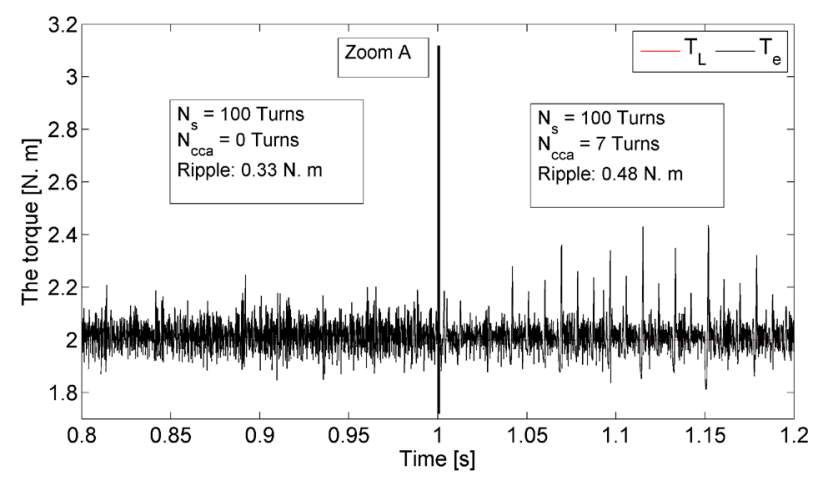

Fig. 16 The zoom A
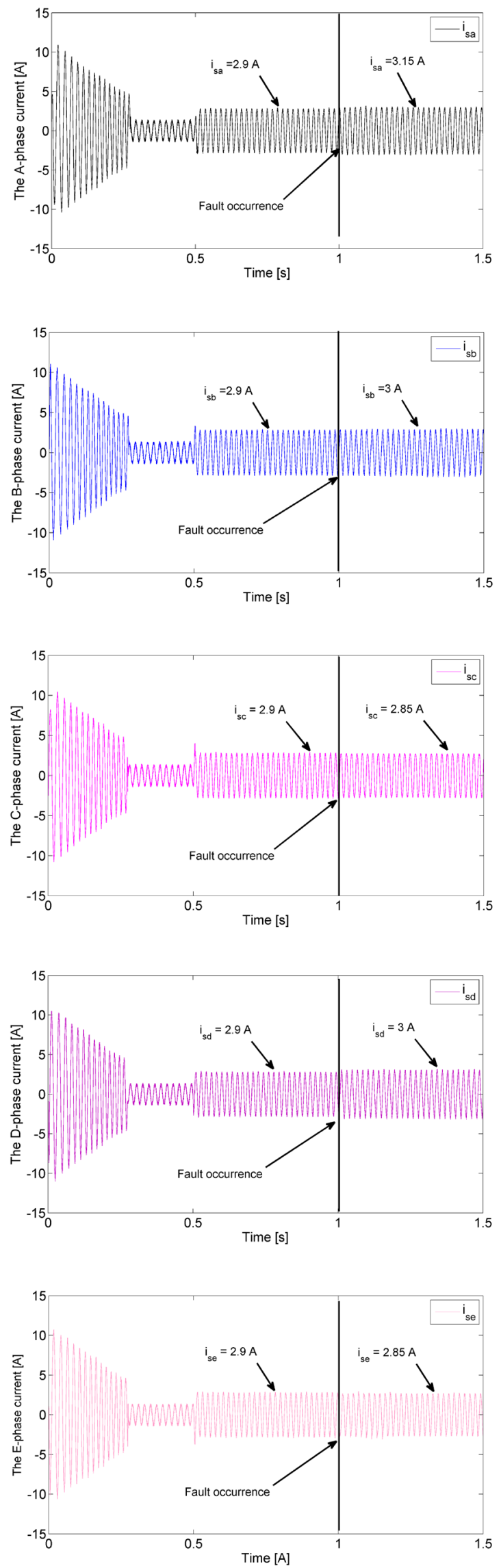

Fig. 17 The five phase stator currents 
more than the b, c, d, and e phase currents. This increase is related to the number of turns in short-circuit. This is obviously the simultaneous decrease of resistance and the inductance phase in the affected phase of the stator.

The following test is to verify the effectiveness of the proposed observer and the studied motor performance during the different speeds changes (low speed, highspeed, reverse speed and load) under short-circuit which touches $7 \%$ of the turns. It can be seen that the motor runs at four stages, according to the following steps: $300 \mathrm{rad} / \mathrm{s}$, $50 \mathrm{rad} / \mathrm{s},-50 \mathrm{rad} / \mathrm{s},-300 \mathrm{rad} / \mathrm{s}$, respectively, which covers practically the full range of motor running speeds. Fig. 18 shows the step reference speed, the estimated speed, and the measured speed (real speed) when the machine is subjected to a sequence of speed changes. Again, the estimated and real rotor speeds follow the reference speed accurately during all the phases of the speed changes, and that the motor can operate adequately at low speeds. Hence, the backstepping control based on SMO exhibits good performance under both of fault and speed change, confirming the effectiveness of the SMO. Also, it can be seen that the speed estimation error is approximately zero in Fig. 19. The electromagnetic torque and the five phase stator currents are presented in Figs. 20 and 21. It can be

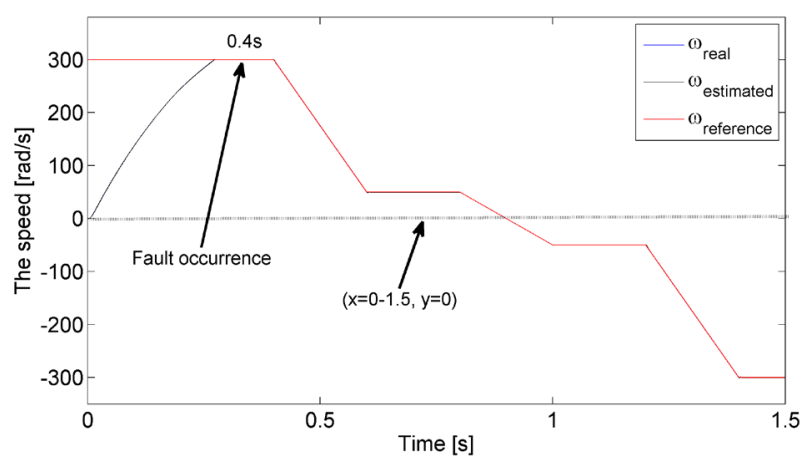

Fig. 18 The real, reference and estimated speed

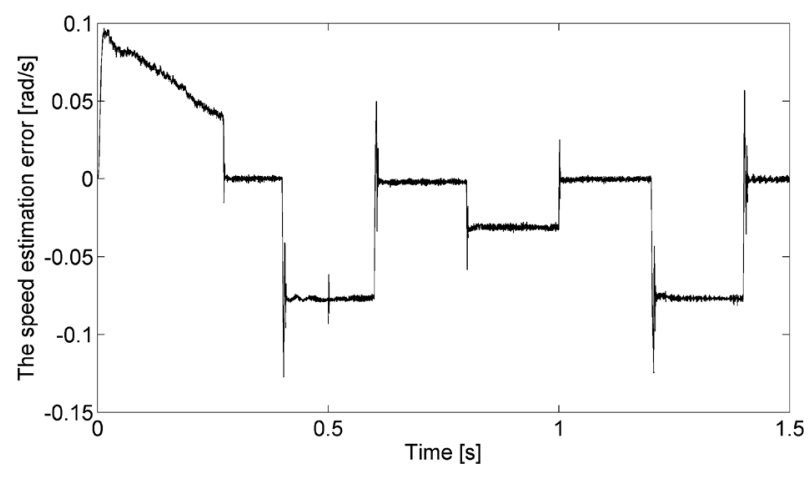

Fig. 19 The speed estimation error

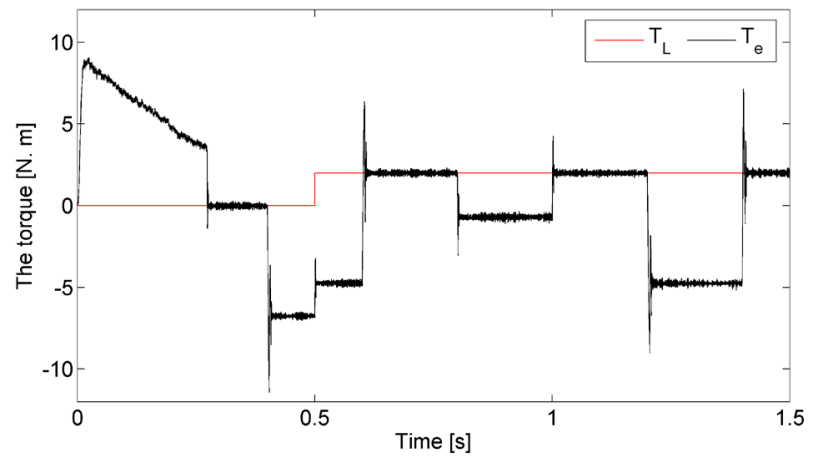

Fig. 20 The electromagnetic and load torque

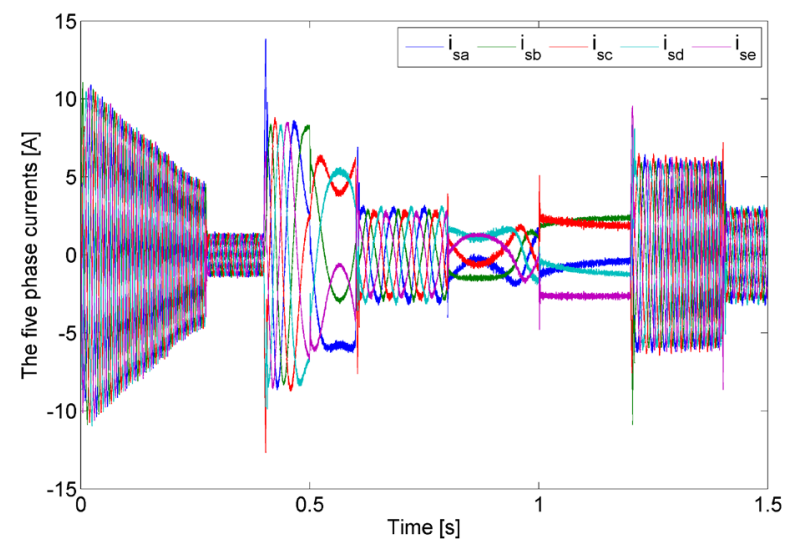

Fig. 21 The five phase stator currents

stated that the values of the torque and the stator currents depend on the working states of the motor.

\subsection{Performances evaluation during parameter variation}

In this test, the influences of parameter variations are investigated in order to test the sensitivity of the proposed SM-Observer. Indeed, to show the robustness of the proposed control scheme, the initial stator resistance is set at its nominal value $R_{s}=7.58 \Omega$. Then, the stator resistance of the motor model is suddenly set to $9.1 \Omega$ at $t=1 \mathrm{~s}$, meanwhile the rotor resistance is changed from $6.3 \Omega$ to $7.56 \Omega$ at the same instant $t=1 \mathrm{~s}$. In this case, the rotor and stator motor resistances used in the controller design are $20 \%$ smaller than the real values as shown in Fig. 22. This situation can be occurred due to the machine heating, if the temperature rises, motor resistance rises as well. Thus, the values used in the observer become smaller than the real one. The reference speed was firstly set to $50 \mathrm{rad} / \mathrm{s}$ under constant load which is approximately equals to 2 N.m. whereas, the reference rotor-flux is maintained at $1.0 \mathrm{~Wb}$. 


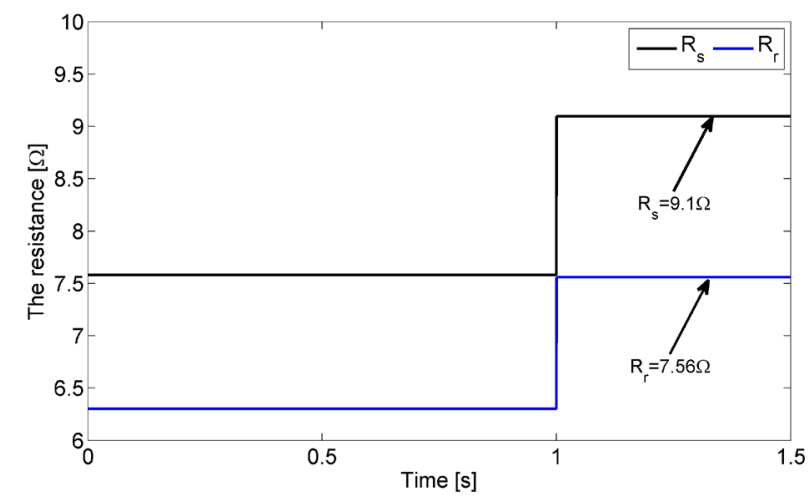

Fig. 22 The motor resistances variation

It is important to note that in this test only the sliding function has been changed from $S_{s \alpha \beta}=\hat{i}_{s \alpha \beta}-i_{s \alpha \beta}$ to $S_{s \alpha \beta}=\frac{\hat{i}_{s \alpha \beta}-i_{s \alpha \beta}+\lambda}{\int \hat{i}_{s \alpha \beta}-i_{s \alpha \beta} d t}$, where $\lambda$ is a positive scalar. This will guarantee the elimination of the static errors in case of ill-known parameters or in case of the application of external perturbations.

The speed responses, the speed estimation error, the torque and the rotor flux are shown in Figs. 23-26 respectively. It can be observed clearly that the obtained

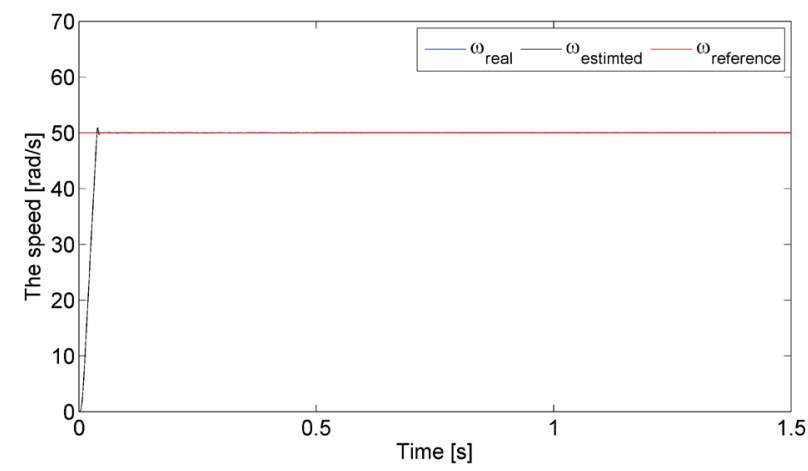

Fig. 23 The real, reference and estimated speed

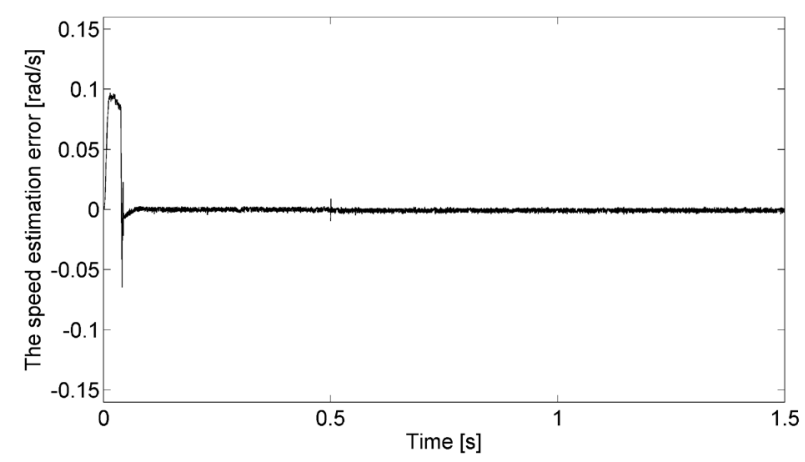

Fig. 24 The speed estimation error

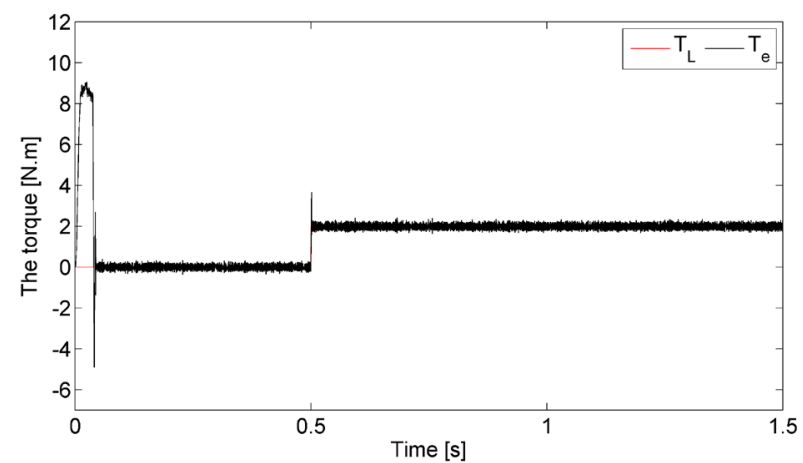

Fig. 25 The electromagnetic and load torque

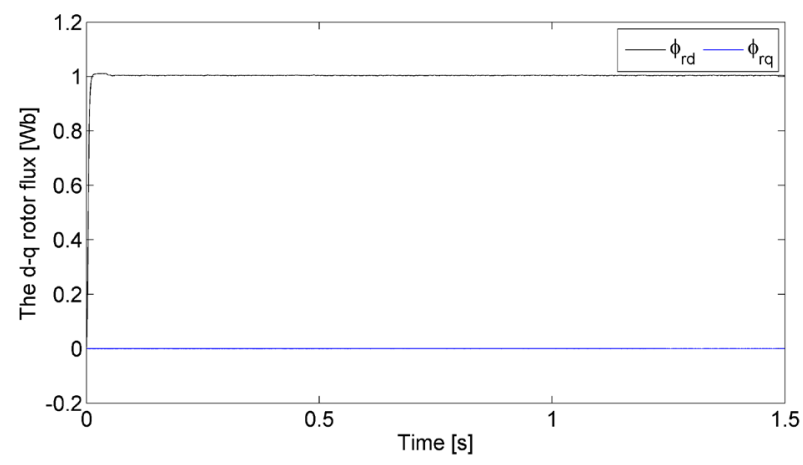

Fig. 26 The $d-q$ rotor flux

model speed (real speed of the motor) and the estimated speed obtained based on the used estimator, have tracked the reference speed adequately as shown in Fig. 23, where the estimation error between the real speed and the estimated speed in nearly neglected which indicates the good accuracy and dynamics of the proposed speed estimator.

On the other side, the proposed control allows maintaining the flux when the motor resistance undergoes variation as shown in Fig. 25. The obtained results in Figs. 23-26, are quite similar to those obtained in the first case (Figs. 6-8 and Fig. 10). Finally, it can be concluded that the obtained results confirm clearly that the proposed control strategy in this paper is distinctly robust against the variation of the studied motor parameters during operating state such as the rotor resistance and the stator resistance, where the studied OEW-FPIM does not lose the stability against the investigated operation conditions. These main outstanding features resulting from the application of the proposed backstepping control technique on the OEW-FPIM will permit to such motor to be used in several indusial applications, where the main problems, which can be faced practically, are frankly overcome. 


\section{Conclusion}

Based on the four tests performed in this paper, it can be said that the proposed backstepping control which is based on the SMO, is able to ensure the tracking of the speed reference with better performance under different speed constraints such as the speed reference variation, the speed reference inversion, the low speed, the variation of parameters and under load disturbances. Furthermore, the obtained results confirm that the proposed backstepping

\section{References}

[1] Khadar, S., Kouzou, A., Hafaifa, A., Iqbal, A. "Investigation on SVM-Backstepping sensorless control of five-phase open-end winding induction motor based on model reference adaptive system and parameter estimation", Engineering Science and Technology, an International Journal, 2019.

https://doi.org/10.1016/j.jestch.2019.02.008

[2] Cao, W., Mecrow, B. C., Atkinson, G. J., Bennett, J. W. "Overview of Electric Motor Technologies Used for More Electric Aircraft (MEA)", IEEE Transactions on Industrial Electronics, 59(9), pp. 3523-3531, 2012.

https://doi.org/10.1109/TIE.2011.2165453

[3] Duran, M. J., Barrero, F. "Recent Advances in the Design, Modeling and Control of Multiphase Machines - Part II", IEEE Transactions on Industrial Electronics, 63(1), pp. 459-468, 2016.

https://doi.org/10.1109/TIE.2015.2448211

[4] Levi, E. "Advances in Converter Control and Innovative Exploitation of Additional Degrees of Freedom for Multiphase Machines", IEEE Transactions on Industrial Electronics, 63(1), pp. 433-448, 2016. https://doi.org/10.1109/tie.2015.2434999

[5] de Lillo, L., Empringham, L., Wheeler, P. W., Khwan-On, S., Gerada, C., Othman, M. N., Huang, X. "Multiphase Power Converter Drive for Fault-Tolerant Machine Development in Aerospace Applications", IEEE Transactions on Industrial Electronics, 57(2), pp. 575-583, 2010.

https://doi.org/10.1109/tie.2009.2036026

[6] Jones, M., Satiawan, I. N. W., Bodo, N., Levi, E. "A Dual Five-Phase Space-Vector Modulation Algorithm Based on the Decomposition Method", IEEE Transactions on Industry Applications, 48(6), pp. 2110-2120, 2012. https://doi.org/10.1109/tia.2012.2226422

[7] Khadar, S., Kouzou, A. "Implementation of Control Strategy Based on SVM for Open-End Winding Induction Motor with short circuit fault between turns in Stator Windings", Journal of Automation \& Systems Engineering, 12(3), pp. 12-25, 2018.

[8] Kalaiselvi, J., Srinivas, S. "Bearing Currents and Shaft Voltage Reduction in Dual-Inverter-Fed Open-End Winding Induction Motor With Reduced CMV PWM Methods", IEEE Transactions on Industrial Electronics, 62(1), pp. 144-152, 2015.

https://doi.org/10.1109/tie.2014.2336614

[9] Wang, Y., Panda, D., Lipo, T. A., Pan, D. "Open-Winding Power Conversion Systems Fed by Half-Controlled Converters", IEEE Transactions on Power Electronics, 28(5), pp. 2427-2436, 2013. https://doi.org/10.1109/tpel.2012.2218259 strategy has the ability of rejecting the effect of stator faults. Indeed, based on testes performed, the proposed control has ensured excellent performance of the motor studied in this paper under short circuit fault between coils. Finally, it is clear that the proposed control based on backstepping presents several interesting advantages in favor of applications where the highest reliability is required, especially in industrial applications.

[10] Khadar, S., Kouzou, A. "A new modeling method for turn to turn fault in same phase of five phase induction motor with open-end stator winding", presented at Second International Conference on Electrical Engineering ICEEB'2018, Biskra, Algeria, Dec., 2-3, 2018.

[11] Delpha, C., Diallo, D., Benbouzid, M. E. H., Marchand, C. "Application of classification methods in fault detection and diagnosis of inverter fed induction machine drive: a trend towards reliability", The European Physical Journal Applied Physics, 43(2), pp. 245-251, 2008.

https://doi.org/10.1051/epjap:2008118

[12] Benbouzid, M. E. H., Diallo, D., Zeraoulia, M. "Advanced FaultTolerant Control of Induction-Motor Drives for EV/HEV Traction Applications: From Conventional to Modern and Intelligent Control Techniques", IEEE Transactions on Vehicular Technology, 56(2), pp. 519-528, 2007.

https://doi.org/10.1109/tvt.2006.889579

[13] Campos-Delgado, D. U., Martinez-Martinez, S., Zhou, K. "Integrated fault-tolerant scheme for a DC speed drive", IEEE/ASME Transactions on Mechatronics, 10(4), pp. 419-427, 2005. https://doi.org/10.1109/tmech.2005.852494

[14] Mendes, A. M. S., Cardoso, A. J. M. "Fault-Tolerant Operating Strategies Applied to Three-Phase Induction-Motor Drives", IEEE Transactions on Industry Applications, 53(6), pp. 1807-1817, 2006. https://doi.org/10.1109/tie.2006.885137

[15] Thomson, W. T., Fenger, M. "Current signature snalysis to detect induction motor faults", IEEE Industry Applications Magazine, 7(4), pp. 26-34, 2001.

https://doi.org/10.1109/2943.930988

[16] Bouzid, M. B. K., Champenois, G., Bellaaj, N. M., Signac, L., Jelassi, K. "An Effective Neural Approach for the Automatic Location of Stator Interturn Faults in Induction Motor", IEEE Transactions on Industrial Electronics, 55(12), pp. 4277-4289, 2008. https://doi.org/10.1109/TIE.2008.2004667

[17] Khadar, S., Kouzou, A. "Fault-tolerant control of asynchronous machine taking into account faults", In: International Conference Electrical Sciences and Technologies in Maghreb (CISTEM), Algiers, Algeria, 2018, pp. 1-7. https://doi.org/10.1109/CISTEM.2018.8613442

[18] Sharifi, R., Ebrahimi, M. "Detection of stator winding faults in induction motors using three-phase current monitoring", ISA Transactions, 50(1), pp. 14-20, 2011. https://doi.org/10.1016/j.isatra.2010.10.008 
[19] Siddique, A., Yadava, G. S., Singh, B. "A review of stator fault monitoring techniques of induction motors", IEEE Transactions on Energy Conversion, 20(1), pp. 106-114, 2005.

https://doi.org/10.1109/TEC.2004.837304

[20] Ballal, M. S., Suryawanshi, H. M., Mishra, M. K. "Stator Winding Inter-turn Insulation Fault Detection in Induction Motors by Symmetrical Components Method", Electric Power Components and Systems, 36(7), pp. 741-753, 2008. https://doi.org/10.1080/15325000701881993

[21] Grubic, S., Aller, J. M., Lu, B., Habetler, T. G. "A Survey on Testing and Monitoring Methods for Stator Insulation Systems of Low-Voltage Induction Machines Focusing on Turn Insulation Problems", IEEE Transactions on Industrial Electronics, 55(12), pp. 4127-4136, 2008. https://doi.org/10.1109/TIE.2008.2004665

[22] Jagadanand, G., Gopi, L., George, S., Jacob, J. "Inter-Turn Fault Detection in Induction Motor Using Stator Current Wavelet Decomposition", International Journal of Electrical Engineering and Technology, 3(2), pp. 103-122, 2012.

[23] Palácios, R. H. C., da Silva, I. N., Goedtel, A., Godoy, W. F., Lopes, T. D. "Diagnosis of Stator Faults Severity in Induction Motors Using Two Intelligent Approaches", IEEE Transactions on Industrial Informatics, 13(4), pp. 1681-1691, 2017. https://doi.org/10.1109/TII.2017.2696978

[24] Soualhi, A., Clerc, G., Razik, H., Lebaroud, A. "Fault Detection and Diagnosis of Induction Motors Based on Hidden Markov Model", In: $2012 \mathrm{XX}^{\text {th }}$ International Conference on Electrical Machines, Marseille, France, 2012, pp. 1693-1699. https://doi.org/10.1109/ICElMach.2012.6350108

[25] Khadar, S., Kouzou, A. "Comparative study between the direct torque control and backstepping control of induction motor under stator fault conditions", presented at Second International Conference on Electrical Engineering ICEEB'2018, Biskra, Algeria, Dec., 2-3, 2018.

[26] Singh, G. K., Al Kazzaz, S. A. S. "Induction machine drive condition monitoring and diagnostic research - A survey", Electric Power Systems Research, 64(2), pp. 145-158, 2003. https://doi.org/10.1016/S0378-7796(02)00172-4

[27] Boumegoura, T. "Recherche de signature électromagnétique des défauts dans une machine synchrone, et synthèse d'observateurs en vue du diagnostic", (Research of electromagnetic signatures of defaults in induction machine and synthesising of adapted observers to diagnosis) PhD Thesis, École Centrale de Lyon, Ecully, France, 2001. (in French) [online] Available at: http://www.theses. fr/2001ECDL0008 [Accessed: 02 May 2019]

[28] Khodla, D. E., Kheldoun, A. "Three-phases Model of the Induction Machine Taking Account the Stator Faults", International Journal of Mechanical and Mechatronics Engineering, 3(4), pp. 363-366, 2009. [online] Available at: https://waset.org/publications/8793 [Accessed: 02 May 2019]

[29] Raisemche, A., Boukhnifer, M., Larouci, C., Diallo, D. "Two Active Fault-Tolerant Control Schemes of Induction-Motor Drive in EV or HEV", IEEE Transactions on Vehicular Technology, 63(1), pp. 19-29, 2014.

https://doi.org/10.1109/tvt.2013.2272182
[30] Lascu, C., Boldea, I., Blaabjerg, F. "Direct Torque Control of Sensorless Induction Motor Drives: A Sliding-Mode Approach", IEEE Transactions on Industry Applications, 40(2), pp. 582-590, 2004.

https://doi.org/10.1109/tia.2004.824441

[31] Li, J., Xu, L., Zhang, Z. "An Adaptive Sliding-Mode Observer for Induction Motor Sensorless Speed Control", IEEE Transactions on Industry Applications, 41(4), pp. 1039-1046, 2005. https://doi.org/10.1109/tia.2005.851585

[32] Imen, H. B., Hajji, S., Chaari, A. "Backstepping Controller Design using a High Gain Observer for Induction Motor", International Journal of Computer Applications, 23(3), pp. 1-6, 2011. https://doi.org/10.5120/2873-3730

[33] Moutchou, M., Abbou, A., Mahmoudi, H. "MRAS-based sensorless speed backstepping control for induction machine, using a flux sliding mode observer", Turkish Journal of Electrical Engineering and Computer Sciences, 23(1), pp. 187-200, 2015. https://doi.org/10.3906/elk-1208-50

[34] Trabelsi, R., Khedher, A., Mimouni, F. M., M'Sahli, F. "An Adaptive Backstepping Observer for on-line rotor resistance adaptation", International Journal of Sciences and Techniques of Automatic Control and Computer Engineering, 4(1), pp. 1246-1267, 2010.

[35] Bennassar, A. Abbou, A. Akherraz, M., Barara, M. "Sensorless Backstepping Control Using an Adaptive Luenberger Observer with Three Levels NPC Inverter", International Journal of Computer, Electrical, Automation, Control and Information Engineering, 7(8), pp. 1171-1177, 2013.

[36] Kwan, C. M., Lewis, F. L. "Robust backstepping control of induction motors using neural network", IEEE Transactions on Neural Networks, 11(5), pp. 1178-1187, 2000. https://doi.org/10.1109/72.870049

[37] Regaya, C. B., Farhani, F., Zaafouri, A., Chaari, A. "An Adaptive Sliding-Mode Speed Observer for Induction Motor under Backstepping Control", ICIC Express Letters, 11(4), pp. 763-771, 2017.

[38] Amara, Y., Barakat, G. "Modeling and Diagnostic of Stator Faults in Induction Machines Using Permeance Network Method", In: Progress In Electromagnetics Research Symposium (PIERS), Marrakesh, Morocco, 2011, pp. 1550-1559.

[39] Khadar, S., Kouzou, A., Rezaoui, M. M., Benguesmia, H. "Comparative Study Between the Field Oriented Control and Backstepping Control of Open- End Winding Five-Phase Induction Motor under Open Phase Fault Conditions", presented at International Conference Symposium on Technology \& Sustainable Industry Development, ISTSID'2019, El-Oued, Algeria, Feb., 2-3, 2019.

[40] Thomas, W., Vasudevan, K., Kumar, V. J. "Online Cage Rotor Fault Using Air-Gap Torque Spectra", IEEE Power Engineering Review, 22(7), pp. 51-52, 2002. https://doi.org/10.1109/mper.2002.4312368

[41] Satiawan, I. N. W., Citarsa, I. B. F., Wiryajati, I. K., Aware, M. V. "Performance Comparison of PWM Schemes of Dual-inverter FED Five-phase Motor Drives", International Journal of Technology, 5(3), pp. 277-286, 2014. https://doi.org/10.14716/ijtech.v5i3.609 
[42] Taoussi, M., Karim, M., Bossoufi, B., Hammoumi, D., Lagrioui, A., Derouich, A. "Speed variable adaptive backstepping control of the doubly-fed induction machine drive", International Journal of Automation and Control, 10(1), pp. 12-33, 2016. https://doi.org/10.1504/IJAAC.2016.075140

[43] Elazzaoui, M. "Modeling and Control of a Wind System Based Doubly Fed Induction Generator: Optimization of the Power Produced", Journal of Electrical and Electronic Systems, 4(1), article ID: 1000141, 2015.

https://doi.org/10.4172/2332-0796.1000141

[44] Tzou, Y.-Y., Hsu, H.-J. "FPGA realization of space-vector PWM control IC for three phase PWM inverters", IEEE Transactions on Power Electronics, 12(6), pp. 953-963, 1997. https://doi.org/10.1109/63.641493

[45] Levi, E., Jones, M., Vukosavic, S. N., Toliyat, H. A. "A Five-Phase Two-Machine Vector Controlled Induction Moto Drive Supplied from a Single Inverter", European Power Electronics and Drives, 14(3), pp. 38-48, 2004.

https://doi.org/10.1080/09398368.2004.11463564

\section{Appendix}

The used coefficients are defined as:

$$
\begin{aligned}
& \Delta_{a 1}=A_{1} i_{s a}+A_{2} i_{s b}+A_{3} i_{s c}+A_{4} i_{s d}+A_{5} i_{s e} \\
& \Delta_{a 2}=k f_{s a} f_{s b}^{2} f_{s c}^{2} f_{s d}^{2} f_{s e}^{2}\left(G \varphi_{s a}+G_{1} \varphi_{s b}-G_{2} \varphi_{s c}+G_{1} \varphi_{s d}-G_{2} \varphi_{s e}\right) \\
& \Delta_{b 1}=B_{1} i_{s a}+B_{2} i_{s b}+B_{3} i_{s c}+B_{4} i_{s d}+B_{5} i_{s e} \\
& \Delta_{b 2}=k f_{s a}^{2} f_{s b} f_{s c}^{2} f_{s d}^{2} f_{s e}^{2}\left(-G_{2} \varphi_{s a}+G \varphi_{s b}+G_{1} \varphi_{s c}-G_{2} \varphi_{s d}+G_{1} \varphi_{s e}\right) \\
& \Delta_{c 1}=C_{1} i_{s a}+C_{2} i_{s b}+C_{3} i_{s c}+C_{4} i_{s d}+C_{5} i_{s e} \\
& \Delta_{c 2}=k f_{s a}^{2} f_{s b}^{2} f_{s c} f_{s d}^{2} f_{s e}^{2}\left(G_{1} \varphi_{s a}-G_{2} \varphi_{s b}+G \varphi_{s c}+G_{1} \varphi_{s d}-G_{2} \varphi_{s e}\right) \\
& \Delta_{d 1}=D_{1} i_{s a}+D_{2} i_{s b}+D_{3} i_{s c}+D_{4} i_{s d}+D_{5} i_{s e} \\
& \Delta_{d 2}=k f_{s a}^{2} f_{s b}^{2} f_{s c}^{2} f_{s d} f_{s e}^{2}\left(-G_{2} \varphi_{s a}+G_{1} \varphi_{s b}-G_{2} \varphi_{s c}+G \varphi_{s d}+G_{1} \varphi_{s e}\right) \\
& \Delta_{e 1}=E_{1} i_{s a}+E_{2} i_{s b}+E_{3} i_{s c}+E_{4} i_{s d}+E_{5} i_{s e} \\
& \Delta_{e 2}=k f_{s a}^{2} f_{s b}^{2} f_{s c}^{2} f_{s d}^{2} f_{s e}\left(G_{1} \varphi_{s a}-G_{2} \varphi_{s b}+G_{1} \varphi_{s c}-G_{2} \varphi_{s d}+G \varphi_{s e}\right) \\
& \phi_{a 1}=\left(f_{s a} i_{s a}-\frac{f_{s b} i_{s b}}{2}-\frac{f_{s c} i_{s d}}{2}-\frac{f_{s d} i_{s d}}{2}-\frac{f_{s e} i_{s e}}{2}\right) \\
& \phi_{a 2}=-k_{A 1} \varphi_{r a}-k_{A 2} \varphi_{r b}-k_{A 3} \varphi_{r c}-k_{A 2} \varphi_{r d}-k_{A 3} \varphi_{r e} \\
& \phi_{b 1}=\left(-\frac{f_{s a} i_{s a}}{2}+f_{s b} i_{s b}-\frac{f_{s c} i_{s c}}{2}-\frac{f_{s d} i_{s d}}{2}-\frac{f_{s e} i_{s e}}{2}\right) \\
& \phi_{b 2}=-k_{A 3} \varphi_{r a}-k_{A 1} \varphi_{r b}-k_{A 2} \varphi_{r c}-k_{A 3} \varphi_{r d}-k_{A 2} \varphi_{r e} \\
& \left\{\phi_{c 1}=\left(-\frac{f_{s a} i_{s a}}{2}-\frac{f_{s b} i_{s b}}{2}+f_{s c} i_{s c}-\frac{f_{s d} i_{s d}}{2}-\frac{f_{s e} i_{s e}}{2}\right)\right. \text {. } \\
& \phi_{c 2}=-k_{A 2} \varphi_{r a}-k_{A 3} \varphi_{r b}-k_{A 1} \varphi_{r c}-k_{A 2} \varphi_{r d}-A_{3} \varphi_{r e} \\
& \phi_{d 1}=\left(-\frac{f_{s a} i_{s a}}{2}-\frac{f_{s b} i_{s b}}{2}-\frac{f_{s c} i_{s c}}{2}+f_{s d} i_{s d}-\frac{f_{s e} i_{s e}}{2}\right) \\
& \phi_{d 2}=-k_{A 3} \varphi_{r a}-k_{A 2} \varphi_{r b}-k_{A 3} \varphi_{r c}-k_{A 1} \varphi_{r d}-k_{A 2} \varphi_{r e} \\
& \phi_{e 1}=\left(-\frac{f_{s a} i_{s a}}{2}-\frac{f_{s b} i_{s b}}{2}-\frac{f_{s c} i_{s c}}{2}-\frac{f_{s d} i_{s d}}{2}+f_{s e} i_{s e}\right) \\
& \phi_{e 2}=-k_{A 2} \varphi_{r a}-k_{A 3} \varphi_{r b}-k_{A 2} \varphi_{r c}-k_{A 3} \varphi_{r d}-k_{A 1} \varphi_{r e}
\end{aligned}
$$

[46] Inanc, N. "A robust sliding mode flux and speed observer for speed sensorless control of an indirect field oriented induction motor drives", Electric Power Systems Research, 77(12), pp. 1681-1688, 2007.

https://doi.org/10.1016/j.epsr.2006.11.015

[47] Gadoue, S. M., Giaouris, D., Finch, J. W. "MRAS Sensorless Vector Control of an Induction Motor Using New Sliding-Mode and Fuzzy-Logic Adaptation Mechanisms", IEEE Transactions on Energy Conversion, 25(2) pp. 394-402, 2010. https://doi.org/10.1109/tec.2009.2036445

[48] Nordin, K. B., Novotny, D. W., Zinger, D. S. "The Influence of Motor Parameter Deviations in Feedforward Field Orientation Drive Systems", IEEE Transactions on Industry Applications, IA-21(4), pp. 1009-1015, 1985. https://doi.org/10.1109/tia.1985.349571 